\title{
Nanofibrillated celluloses for the performance improvement of ultra-high ductility cementitious composites
}

\section{Long Liang}

Shandong Jianzhu University

\section{Xin Zhang}

Shandong Jianzhu University

Qiaoling Liu (D IqI263@163.com )

Shandong Jianzhu University https://orcid.org/0000-0003-0525-9663

\section{Xiurong Li}

Engineering Research Institute of Appraisal and Strengthening of Shandong Jianzhu University

\section{Research Article}

Keywords: Nanofibrillated cellulose (CNF), Ultra-high ductility cementitious composites (UHDCC), Rheology, Low-field nuclear magnetic resonance (LF-NMR), Tensile strain-hardening capacity

Posted Date: September 10th, 2021

DOl: https://doi.org/10.21203/rs.3.rs-878655/v1

License: (9) This work is licensed under a Creative Commons Attribution 4.0 International License. Read Full License 


\title{
Nanofibrillated celluloses for the performance improvement of ultra-high ductility cementitious composites
}

\author{
Long Liang
}

School of Civil Engineering, Shandong Jianzhu University, Jinan 250101, China

Engineering Research Institute of Appraisal and Strengthening of Shandong Jianzhu University, Jinan 250101, China

Xin Zhang $\cdot$ Qiaoling Liu $(\bowtie)$

School of Civil Engineering, Shandong Jianzhu University, Jinan 250101, China

Key Laboratory of Building Structural Retrofitting and Underground Space Engineering of Ministry of Education, Jinan 250101, China

Engineering Research Institute of Appraisal and Strengthening of Shandong Jianzhu University, Jinan 250101, China

Corresponding authors: 1q1263@163.com (Q. Liu)

Xiurong Li

Engineering Research Institute of Appraisal and Strengthening of Shandong Jianzhu University, Jinan 250101, China

\section{Abstract}

This study explored the effect of nanofibrillated celluloses (CNF), namely $0 \%, 0.05 \%, 0.1 \%$, and $0.15 \%$ of binders weight, on the hydration, rheology, pore structure, and mechanical properties of ultra-high ductility cementitious composites (UHDCC). The hydration kinetics were conducted with different $\mathrm{CNF}$ contents using isothermal calorimetry (IC), showing a retardation effect of $\mathrm{CNF}$ on the early hydration of UHDCC matrices at $70 \mathrm{~h}$ due to the absorption of CNF on the surface of cement particles. Then, thermogravimetric analysis (TGA) demonstrated that CNF improved the degree of hydration at 28 days due to the formation of the CNF transport of water into unhydrated cement cores. The two rheological parameters, namely the yield stress and plastic viscosity, of the fresh UHDCC matrices increased with the increasing CNF contents. Low-field nuclear magnetic resonance (LF-NMR) analysis, as a non-destructive method, proved that the addition of CNF could reduce the porosity of UHDCC and refine its pore size distribution, and the 8.9-46.1\% enhancement in the compressive strength of corresponding specimens was found. Notably, CNF could increase the tensile initial cracking stress by $91.2 \%$ and tensile stress by $30.8 \%$ of UHDCC, and maintain or increase its over $8 \%$ of tensile strain-hardening capacity. The flexural tests also were found a $54.6 \%$ increase in the initial stress and a $14.8 \%$ increase in the peak stress. As a preliminary, CNF shows crucial promising as a greener nanomaterial to improve the strength and ductility of UHDCC. 
Keywords Nanofibrillated cellulose $(C N F) \cdot$ Ultra-high ductility cementitious

composites $(U H D C C) \cdot R$ Reology · Low-field nuclear magnetic resonance (LF-

$N M R) \cdot$ Tensile strain-hardening capacity.

\section{Introduction}

As the traditional construction materials, cement-based materials (CBM) appeared in the 1800s. The brittle of normal CBM reflected the occurrence of sudden failure, and the higher strength tended to be more brittle, which calls in questions for the durability of normal CBM. These problems can be traced to its disability in tensile capacity and crack resistance. Therefore, engineered cementitious composites (ECC) were designed to overcome the lack of deformation capacity ( $\mathrm{Li}$ 2019). ECC is a new type of short-fiber reinforced cementitious composites (FRC) with high ductility. By adding no more than $2 \%$ volume fraction of polyvinyl alcohol (PVA) or polyethylene (PE) fibers, ECC exhibits a tensile strain-hardening behavior with the ultimate tensile strain beyond $2 \%$ (100 times more than normal CBM), multiple cracking with controlled width, high deformation capacity, and so forth. ECC has been investigated for over 30 years and has evolved from PVA-ECC with low and moderate strength grades and a tensile strain capacity of 35\% (Yang et al. 2007; Pan et al. 2018; Zhang et al. 2020b) to PE-ECC with all grades and a tensile strain capacity of up to 8\% (Yu et al. 2017, 2018; Li et al. 2019), and thus PE-ECC was named ultra-high ductility cementitious composites (UHDCC). Due to the absence of coarse aggregates, the cementitious material content for developing high strength UHDCC is obviously higher than conventional concrete, and the high Portland cement content is the most costly and environmentally unfriendly (Wei and Cen 2019) at the same time, which violates the concept of ecological and green construction materials. In recent years, applying nanomaterials to cementbased composites has increasingly been a popular topic, and nanotechnology could modify the properties of cement-based composites, and also reduce $\mathrm{CO}_{2}$ emission and raw materials. Adding various types of nanomaterials, such as multi-walled carbon nanotubes (MWCNTs) (Xu et al. 2019), graphene oxide (GO) ( $\mathrm{Lu}$ et al. 2016), nano-SiO2 (NS) (Li et al. 2016; Xi et al. 2020; Yu et al. 2020; Ding et al. 2021; Zhou et al. 2021), and nano-CaCO3 (NC) (Ding et al. 2020), has been proved to be an effective method for improving the properties of ECC. These nanomaterials could act as nucleation sites and thus accelerate the hydration of cement particles, which would provide more hydration products, and fill the pores. In terms of ECC, the interface properties between matrices and fibers could be improved by the addition of nanomaterials, thereby modifying the mechanical properties of ECC.

Moreover, bio-based nanomaterials, such as nanocelluloses, as green materials have the potential to play the same role as other nanomaterials. Nanocelluloses are the most abundant of all renewable and bio-degradable natural resources in accord with sustainability, low costs, and low risks. Nanocelluloses (Klemm et al. 2011) mainly include microfibrillated celluloses (MFC), cellulose nanocrystals (CNC), nanofibrillated celluloses (CNF), cellulose filaments $(\mathrm{CF})$, and bacterial nanocelluloses (BNC). CNF, that is whiskers and fibrils with a length of 500-5000 nm and a diameter of 50-100 nm, can be extracted from plants, woods, etc. at a nanoscale. It has several unique features such as high aspect ratio, high surface area, low density, and superior mechanical properties (Santos et al. 2021). Among these nanocelluloses, CNF and CF have a higher aspect ratio than others. The application of nanocelluloses in cement-based materials involves the interaction between cement and nanostructured cellulose (Moon et al. 2011). The various effect of nanocelluloses on the hydration kinetics of cement particles was reported, including the retardation or acceleration of heat flow rate at early ages, and the acceleration of the degree of hydration at later ages, which was frequently attributed to the surface absorption characteristic of nanocelluloses (Fu et al. 2017). The short circuit diffusion (SCD) was proposed, and nanocelluloses adhered to the surface of cement particles act as transmission paths to transport 
water to the core of unhydrated cement particles due to their hydrophilicity (Cao et al. 2016a). According to the results of Cao (Cao et al. 2015), an optimal content of CNC could increase the degree of hydration and flexural strength of cement pastes. Liu (Liu et al. 2019) studied the effect of $\mathrm{CNC}$ on the properties of cement pastes and indicated that $\mathrm{CNC}$ had an excellent effect on preventing cement pastes from cracking at low temperatures. Hisseine et.al (Hisseine et al. 2018b, 2019) reported systematically that all mechanical properties, compression, tension, and flexure, for concrete mixtures incorporating CF, were enhanced, and only flexural strength for cement pastes increased. CF also could significantly control the autogenous shrinkage of ultra-high performance concrete (UHPC) with a low water-binder ratio (Hisseine et al. 2020). It has been reported that the addition of CNF exhibited enhancements in the durability, such as sulfate resistance (Goncalves et al. 2019) and freezing-thawing resistance (Barnat-Hunek et al. 2019), of cement-based materials. Besides, CNF also had a beneficial effect on another system of calcium aluminate cement (CAC) (Claramunt et al. 2019) and alkali activated ground granulated blast-furnace slag (GGBS) (Ez-zaki et al. 2021).

To the best of our knowledge, there is lacking existing research on the application of CNF to UHDCC yet. It has been demonstrated that UHDCC can effectively improve their mechanical performance due to the mechanism of fiber bridging ( $\mathrm{Li}$ and Leung 1992). To investigate the interaction between nanoscale fibrils and macroscale fibers at multiple scales, this research systematically studies the effect of CNF on the mechanical properties of UHDCC through uniaxial direct tensile tests, flexural tests, and compressive strength evaluations at a macroscale. The rheological properties of the fresh UHDCC matrices, having a significant effect on the dispersion of fibers, were analyzed. At a microscale, isothermal calorimetry (IC) and thermal gravimetric (TG)/Derivative thermal gravimetric (DTG) tests were conducted to investigate the hydration kinetics of UHDCC matrices. Additionally, the pore size distribution tests were conducted using the low-field nuclear magnetic resonance (LF-NMR) method to evaluate the effect of CNF on the pore structure of UHDCC.

\section{Materials and methods}

\section{Materials}

\section{UHDCC basic compositions}

The raw materials used for preparing UHDCC included ordinary Portland cement (OPC), ground granulated blast furnace flag (GGBS), silica fume (SF), limestone powder (LP), and quartz sand (with a particle size of 120-212 $\mu \mathrm{m}$ ). The chemical compositions of binders and the properties of OPC are listed in Table 1 and Table 2. Moreover, a proper high-range water-reducing admixture (HRWR) was employed to maintain an appropriate flowability of the fresh mixtures.

PE fibers with high strength and high elastic modulus were used to achieve high ductility, and the geometric parameters and mechanical properties of PE fibers are given in Table 3.

Table 1 Chemical compositions of binders (mass\%).

\begin{tabular}{cccccccc}
\hline $\begin{array}{c}\text { Chemical } \\
\text { composition }\end{array}$ & $\mathrm{SiO}_{2}$ & $\mathrm{CaO}$ & $\mathrm{Al}_{2} \mathrm{O}_{3}$ & $\mathrm{Fe}_{2} \mathrm{O}_{3}$ & $\mathrm{SO}_{3}$ & $\mathrm{MgO}$ & $\mathrm{CaCO}_{3}$ \\
\hline OPC & 21.2 & 60.3 & 3.2 & 3.98 & 2.55 & 1.53 & $/$ \\
GGBS & 37.46 & 36.78 & 12.88 & 4.87 & 0.65 & 7.05 & $/$ \\
$\mathrm{SF}$ & 98.16 & 0.39 & 1.13 & 0.98 & $/$ & 0.86 & $/$ \\
LP & 0.28 & $/$ & 0.11 & 0.15 & $/$ & 0.28 & 98.15 \\
\hline
\end{tabular}


Table 2 Properties of OPC.

\begin{tabular}{cccccc}
\hline Material & $\begin{array}{c}\text { Specific gravity } \\
\left(\mathrm{kg} / \mathrm{m}^{3}\right)\end{array}$ & $\begin{array}{c}\text { Cement Blaine } \\
\left(\mathrm{m}^{2} / \mathrm{kg}\right)\end{array}$ & $\begin{array}{c}\text { Initial setting } \\
\text { times }(\mathrm{min})\end{array}$ & $\begin{array}{c}\text { Final setting } \\
\text { times }(\mathrm{min})\end{array}$ & $\begin{array}{c}\text { 28-day Compressive } \\
\text { strength }(\mathrm{MPa})\end{array}$ \\
\hline Cement & 3100 & 350 & 170 & 200 & 58.5 \\
\hline Table 3 Properties of PE fibers. & Diameter $(\mu \mathrm{m})$ & Density $\left(\mathrm{kg} / \mathrm{m}^{3}\right)$ & $\begin{array}{c}\text { Tensile strength } \\
(\mathrm{MPa})\end{array}$ & $\begin{array}{c}\text { Elastic modulus } \\
(\mathrm{GPa})\end{array}$ \\
\hline $\begin{array}{c}\text { Type } \\
\text { Pength }(\mathrm{mm})\end{array}$ & 18 & 24 & 970 & $2900-3000$ & 110 \\
\hline fiber & L & & & & \\
\hline
\end{tabular}

\section{Nanofibrillated cellulose}

Nanofibrillated cellulose (CNF) used in this study was supplied by Shengquan Group Company, Jinan, China in the form of suspensions with a weight content of $0.7 \%$. Fig. 1a shows the TEM image of CNF. CNF had a diameter of 10-50 nm and a length of 500-1000 nm. The molecular structure of CNF was presented by Attenuated total reflection-Fourier transform infrared spectroscopy (ATR-FTIR) with the iS50 FT-IR spectrometer (ThermoFisher Scientific, USA), as shown in Fig. 1b. The spectra were recorded at $4 \mathrm{~cm}^{-1}$ resolution and 32 scans in the $4000-450^{-1}$ wavenumber range. In the spectra of CNF, the peak at $3330 \mathrm{~cm}^{-1}$ is related to $\mathrm{O}-\mathrm{H}$ stretching vibration (in $\mathrm{OH}^{-}$from hydroxyl), and the peak at 2887 is related to $\mathrm{C}-\mathrm{H}$ stretching vibration. The peaks at $1411-897 \mathrm{~cm}^{-1}$ are associated with the vibration of cellulose structures. The $1590 \mathrm{~cm}^{-1}$ band is characterized by $\mathrm{C}=\mathrm{O}$ (in $\mathrm{COO}^{-}$from carboxylic salt) antisymmetric stretching vibration ( $\mathrm{Li}$ et al. 2015), indicating the carboxylate groups were obtained by TEMPOmediated oxidation (Xu et al. 2014). The carboxylate and hydroxyl groups could be contributed to the increase in hydrophilicity of CNF, which imposes a positive effect on the dispersion of CNF into water (Habibi et al. 2006).

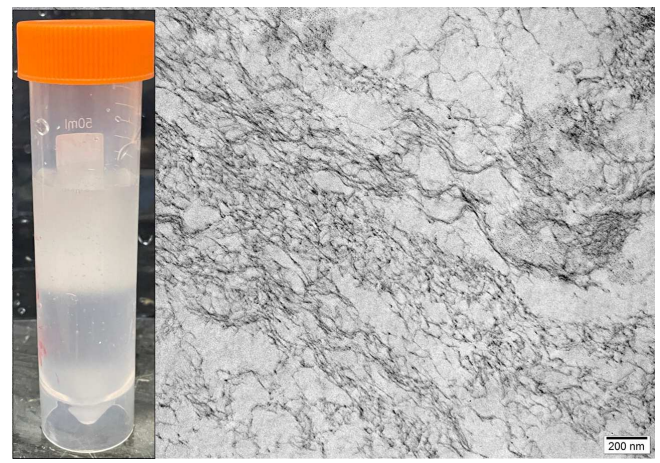

(a) TEM image of CNF

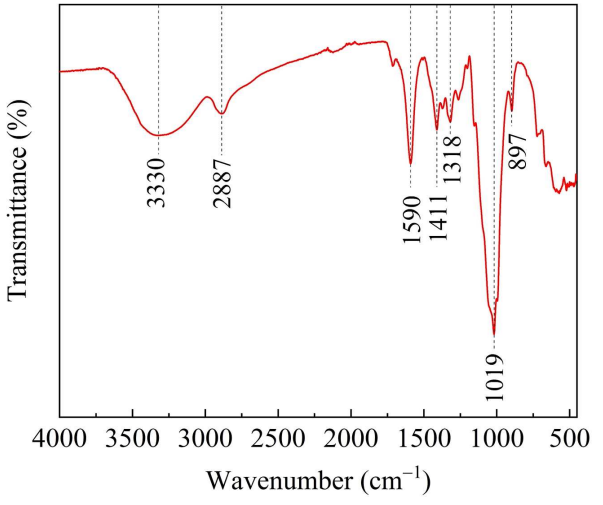

(b) ATR-IR spectra of CNF

Fig. 1 Characterization of CNF

\section{Mixture proportion and mixing procedure}

The mixture proportions are designed and listed in table 4. CNF was added in the fresh matrices with different contents of $0 \%, 0.05 \%, 0.1 \%$, and $0.15 \%$ of the total weight of binders. It should be mentioned that the maximum dosage of CNF in the suspension with $0.07 \%$ solid content 
and $99.3 \%$ water, satisfying the water requirement of $0.22 \mathrm{~W} / \mathrm{B}$, was set to $0.15 \%$ in this study. In order to more uniformly disperse the CNF suspensions, they must be homogenized in advance by magnetic stirring and ultrasonic dispersion in water (Cao et al. 2016b).

The mixing procedure was as followed: a mortar mixer with a capacity of $15 \mathrm{~L}$ was used. Firstly, the raw materials including OPC, GGBS, SF, LP, and quartz sand were mixed for 2 min. Subsequently, water and admixtures, including CNF suspension and HRWR, were added and mixed for another $10 \mathrm{~min}$ to ensure the homogeneity of the fresh mixtures. PE fibers were added slowly and stirred quickly until achieving uniform dispersion. To ensure the workability of UHDCC, the flowability measured by the reciprocating flow table method should reach nearly the same value of about $160 \mathrm{~mm}$ by adjusting the HRWR content, and no bleeding phenomenon should be seen in all mixture proportions. Finally, the fresh UHDCC was cast into steel molds and demolded after curing for 48 hours. All specimens were cured in a standard curing room at a relative humidity of more than $95 \%$ and temperature of $20 \pm 2{ }^{\circ} \mathrm{C}$ for 28 days.

Table 4 Mixture proportions.

\begin{tabular}{|c|c|c|c|c|c|c|c|c|}
\hline \multirow{3}{*}{ Mixture ID } & \multicolumn{7}{|c|}{ Mass fraction } & \multirow{3}{*}{$\begin{array}{c}\begin{array}{c}\text { Volume } \\
\text { fraction }\end{array} \\
\text { PE fiber } \\
(\%)\end{array}$} \\
\hline & \multirow{2}{*}{$\mathrm{W} / \mathrm{B}$} & \multicolumn{3}{|c|}{ Binder } & \multirow{2}{*}{$\mathrm{S} / \mathrm{B}$} & \multirow{2}{*}{ CNF (\%) } & \multirow{2}{*}{$\begin{array}{c}\text { HRWR } \\
(\%)\end{array}$} & \\
\hline & & $\mathrm{C}$ & GGBS & SF & & & & \\
\hline $0.22 \mathrm{~W}-0 \mathrm{CNF}$ & 0.22 & 0.4 & 0.5 & 0.1 & 0.3 & 0 & 0.26 & 2 \\
\hline $0.22 \mathrm{~W}-0.1 \mathrm{CNF}$ & 0.22 & 0.4 & 0.5 & 0.1 & 0.3 & 0.05 & 0.3 & 2 \\
\hline $0.22 \mathrm{~W}-0.1 \mathrm{CNF}$ & 0.22 & 0.4 & 0.5 & 0.1 & 0.3 & 0.1 & 0.36 & 2 \\
\hline $0.22 \mathrm{~W}-0.15 \mathrm{CNF}$ & 0.22 & 0.4 & 0.5 & 0.1 & 0.3 & 0.15 & 0.45 & 2 \\
\hline
\end{tabular}

\section{Test methods}

\section{Isothermal calorimetry (IC)}

The early hydration heat of ECC matrices was measured using a TAM air calorimetry (TA instruments, New Castle). An approximately $10 \mathrm{~g}$ sample of each mixture was sealed into the ampoule and then placed in the calorimetric chamber at a constant temperature of $20 \pm 0.1^{\circ} \mathrm{C}$ for $190 \mathrm{~h}$.

\section{Thermogravimetric analysis (TGA)}

To obtain quantitatively the degree of hydration (DOH) of ECC matrices at later ages, thermal gravimetric (TG) and derivative thermal gravimetric (DTG) were carried out with a Mettler Toledo TGA/SDTA 851 instrument. An approximately $30 \mathrm{mg}$ hardened sample powder at 28 days was heated from $30^{\circ} \mathrm{C}$ to $1000^{\circ} \mathrm{C}$ at a constant rate of $10^{\circ} \mathrm{C} / \mathrm{min}$ under a nitrogen atmosphere.

\section{Rheology}

The fresh UHDCC matrices (without fibers) incorporating different CNF contents were immediately transferred to a container for rheological tests, and all the tests were performed after 10 min of adding water. A rotary rheometer (Kinexus, Malvern, U.K.) was utilized to measure the rheological properties of the fresh matrix at a steady shear rate. Fig. 2 delineates the rheological 
test program, which mainly includes two stages of pre-shearing and data-logging. In the preshearing stage, the shear rate was increased from 0 to $100 \mathrm{~s}^{-1}$ within $30 \mathrm{~s}$ and then decreased to 0 $\mathrm{s}^{-1}$ within $30 \mathrm{~s}$. The purpose of pre-shearing is to make each group of the mortar have the same initial shearing state during the rheological analysis. In the data-logging stage, after completion of the pre-shearing step, and waiting for $30 \mathrm{~s}$, the shear rate was increased from 0 to $100 \mathrm{~s}^{-1}$ within 70 $\mathrm{s}$ and then dropped to 0 within $70 \mathrm{~s}$. A total of 80 data points were collected to draw the shear rateshear stress curve.

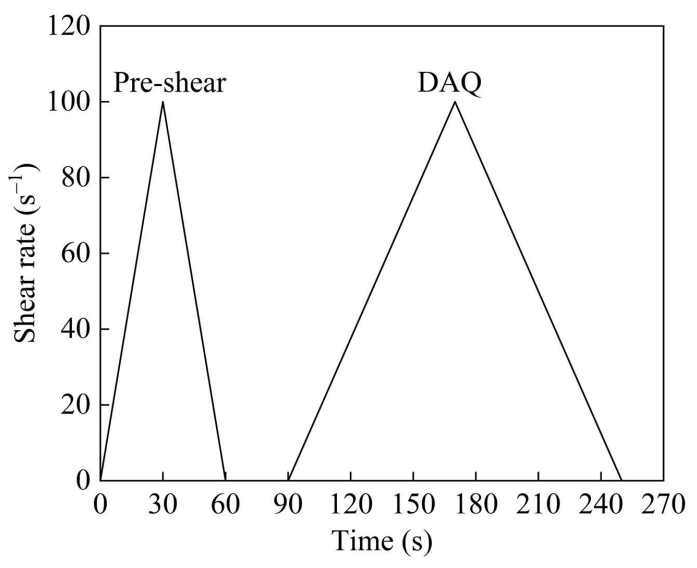

Fig. 2 Rheological test program.

\section{Pore structure}

LF-NMR as a non-destructive method has been employed to measure the pore structure of porous materials, including cement-based materials (Dillinger and Esteban 2014; Bede et al. 2016). The LF-NMR instrument (MesoMR12-60H-I, Suzhou Niumag Analytical Instrument Corporation, Jiangsu, China) was employed on a resonance frequency of $12.75 \mathrm{MHz}$, a magnetic field of $0.4 \mathrm{~T}$, and a radio frequency (RF) coil of $60 \mathrm{~mm}$. The Carr-Purcell-Meiboom-Gill (CPMG) pulse sequences (Muller et al. 2013) were used to obtain Transverse relaxation time $\left(T_{2}\right)$. The CPMG parameters for testing are as follows: Echo Time $(\mathrm{TE})=0.2$, Waiting Time for Repeated $(\mathrm{TW})=$ $8000 \mathrm{~ms}$, Echo Number $(\mathrm{NECH})=15000$, Scanning Number $(\mathrm{NS})=64$.

To this end, the pores of three cube UHDCC specimens at 28 days with a dimension of $40 \times 40$ $\times 40 \mathrm{~mm}$ were vacuum/pressure saturated with liquid water, and then the LF-NMR tests were conducted. In the static magnetic field, the pulsed magnetic field with CPMG sequences was applied repeatedly. The signal intensity of hydrogen protons in water distinguished from different pore sizes was recorded by the LF-NMR instrument (Weng et al. 2019). Then, the transverse relaxation time $\left(T_{2}\right)$ of hydrogen protons was obtained by the signal calibration, converted to the porosity and pore size distribution of the specimens, and the difference in LF-NMR relaxation time can reflect the change of pore size, as follows:

$$
\frac{1}{T_{2}} \approx \rho_{2} \frac{S}{V}
$$

where $T_{2}$ is transverse relaxation time (ms); $\rho_{2}$ is surface relaxivity $(\mathrm{nm} / \mathrm{ms})$, and its value is generally $12 \mathrm{~nm} / \mathrm{ms}$ (She et al. 2013; Zhao et al. 2018); $S / V$ is specific surface area (equivalent to $2 / r$ if the geometry of pores is assumed to be cylindrical, $r$ is the pore radius (nm) ).

Next, all specimens were dried to a constant mass. Mass of evaporable water was used to quantify the total pore porosity of UHDCC. 


\section{Compressive strength}

After LF-NMR tests, all $40 \mathrm{~mm}$ cube specimens were prepared to measure the 28-day compressive strength of UHDCC. The compressive tests were conducted using a $3000 \mathrm{kN}$ MTS machine at a stress control of $1 \mathrm{MPa} / \mathrm{s}$.

\section{Uniaxial direct tensile tests}

The uniaxial direct tensile tests adopted a type of dog-bone-shaped specimens (see Fig. 3a) to measure the tensile stress-strain curves. At least three specimens were prepared for every mixture proportion. The tensile tests were conducted using a $50 \mathrm{kN}$ microcomputer-controlled electro servo test machine at a constant-velocity displacement of $0.5 \mathrm{~mm} / \mathrm{min}$, and the variation in the middlecross-section of the gauge length of $80 \mathrm{~mm}$ was measured with two linear variable displacement transducers (LVDTs) to calculate the tensile strain. The test setup is shown in Fig. 3 b.

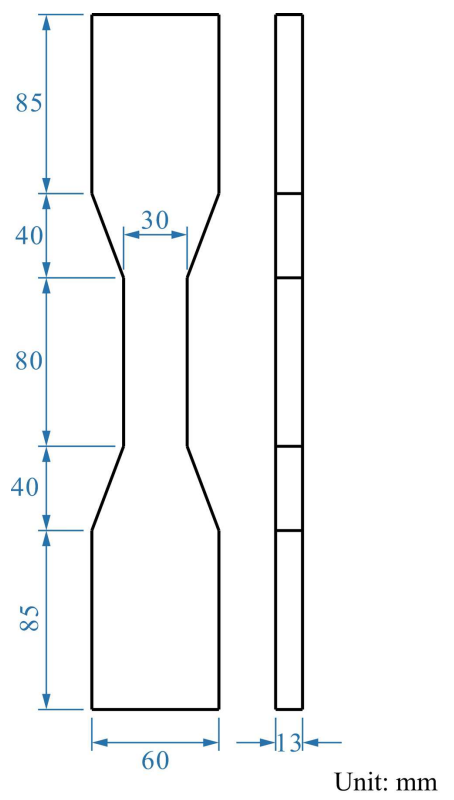

(a) Geometry of dog-bone shaped specimen

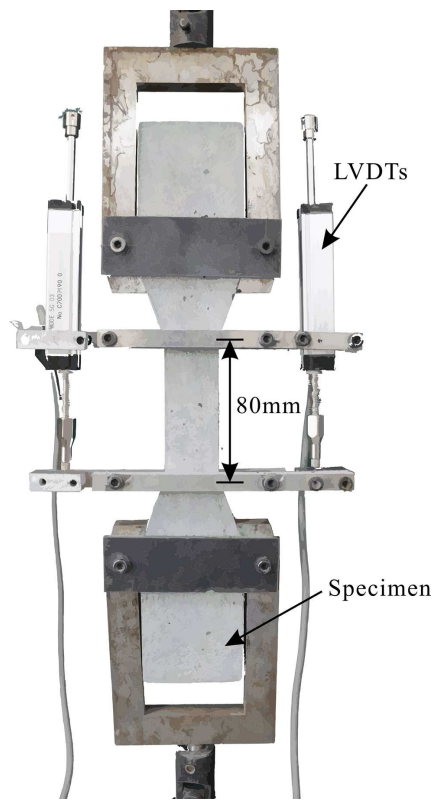

(b) Test setup

Fig. 3 Dog-bone-shaped specimen for tensile test.

To investigate the mechanism of high ductility, according to the micromechanics design theory for UHDCC, the fiber bridging complementary energy $J_{b}^{\prime}$ and the crack tip toughness $J_{\text {tip }}$ were used to calculate the pseudo-strain hardening energy index $\left(P S H_{\mathrm{e}}=J_{b}^{\prime} / J_{t i p}\right)$. The single-crack tensile test was conducted with the notched dog-bone-shaped specimen (Fig. 4a) to obtain the value of $J_{b}^{\prime}$. The notched three-point bending test was conducted to obtain the value of $J_{\text {tip }}$, and the test setup and specimen are shown in Fig. $4 \mathrm{~b}$.
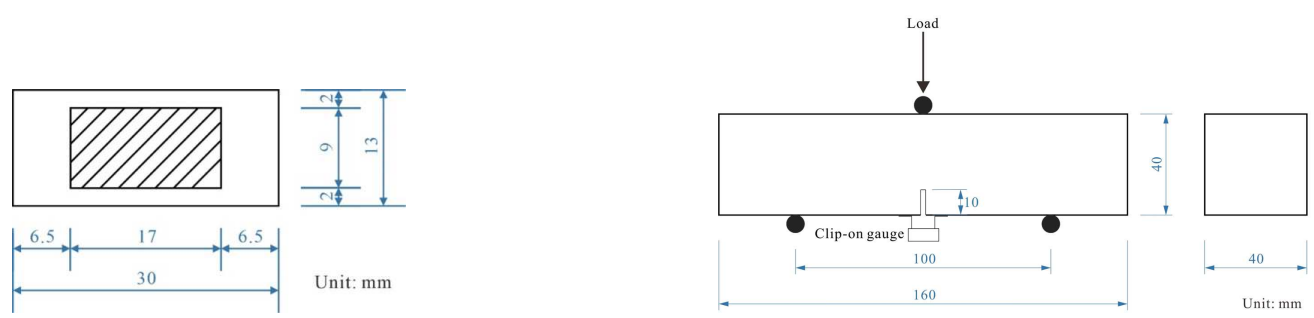
Fig. 4 Pseudo-strain hardening energy index $\left(\mathrm{PSH}_{\mathrm{e}}\right)$ test

\section{Flexural tests}

The flexural specimens were $40 \times 40 \times 160 \mathrm{~mm}$ with a support span of $100 \mathrm{~mm}$. Three-point bending tests were conducted by a $50 \mathrm{kN}$ microcomputer-controlled electro servo test machine at 1 $\mathrm{mm} / \mathrm{min}$, and the mid-span deflection was recorded by LVDTs.

\section{Results}

\section{Early hydration analysis}

Fig. 5 shows the effect of the CNF content on the hydration heat flow rate and total cumulative heat of UHDCC matrices. As indicated in Fig. 5a, the duration of the second exothermic peak with $0.05 \%, 0.1 \%, 0.15 \%$ CNF was prolonged by $1.82 \mathrm{~h}, 3.93 \mathrm{~h}$, and $11.84 \mathrm{~h}$ compared with the control group ( $0 \% \mathrm{CNF}$ ), respectively. On the one hand, the early retardation of the heat flow rate might be attributed to the adsorption of $\mathrm{CNF}$ on the surface of cement particles, reducing the reaction surface area (Ez-zaki et al. 2021). On the other hand, the retardation might be linked to the increase in HRWR demands. Fig. $5 \mathrm{~b}$ shows that the total cumulative heat release with $0.05 \%$ and $0.1 \% \mathrm{CNF}$ surpassed that without CNF after approximately $70 \mathrm{~h}$ and $110 \mathrm{~h}$. It is observed that $0.1 \% \mathrm{CNF}$ has the biggest positive effect on the heat release at the early age of $190 \mathrm{~h}$.

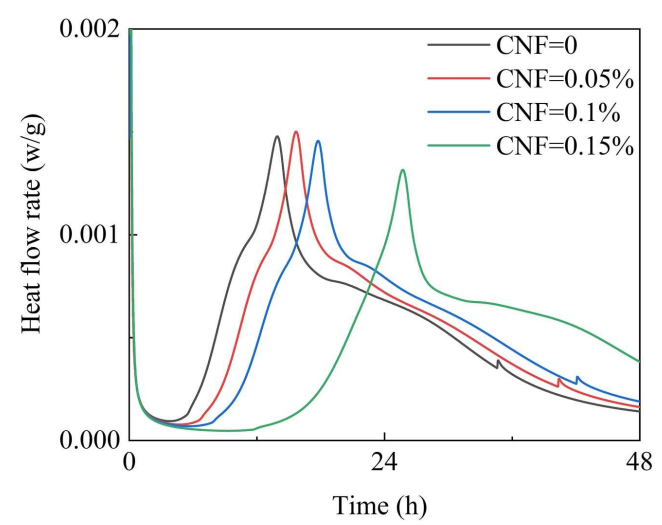

(a) Hydration heat flow rate

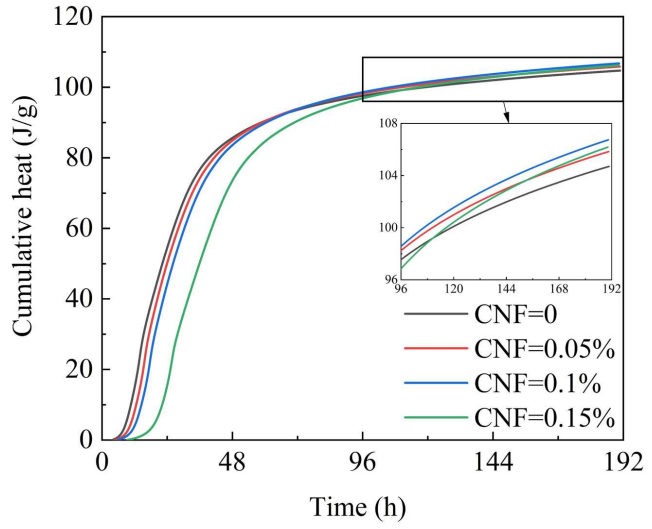

(b) Total cumulative hydration heat release

Fig. 5 Hydration process of UHDCC matrix with different CNF contents.

\section{TGA analysis}

The TGA results of UHDCC matrices at 28 days with different CNF contents are shown in Fig. 6. As shown in Fig. 6a, it is observed that the weight loss of UDCC matrices was enhanced with increasing CNF contents. The weight loss mainly originates from three parts: (1) the first weight loss is observed below $180{ }^{\circ} \mathrm{C}$, relating to the weight loss of water from C-S-H and ettringite; (2) the second weight loss is observed at $380-450{ }^{\circ} \mathrm{C}$, which is owing to the decomposition of $\mathrm{Ca}(\mathrm{OH})_{2}(\mathrm{CH})$; (3) the third weight loss is observed at $600-780{ }^{\circ} \mathrm{C}$, which is attributed to the decomposition of $\mathrm{CaCO}_{3}$. Base on the TGA curves, Then, the degree of hydration (DOH) was 
assessed by the mass proportion of the chemically bound water (CBW) at $140-1000{ }^{\circ} \mathrm{C}$ (EscalanteGarcia 2003; Pane and Hansen 2005), and some weight loss among $600-780{ }^{\circ} \mathrm{C}$ due to decarbonization ( $\left.C \mathrm{O}_{\text {loss }}\right)$ should be reduced, as shown in Eq. (2).

$$
C B W=\frac{W_{\text {loss }}-C O_{\text {loss }}}{W}
$$

where $W_{\text {loss }}$ is the total weight loss of the sample at $140-1000^{\circ} \mathrm{C}$; $C O_{\text {loss }}$ is the weight loss of the sample due to $\mathrm{CO}_{2}$ loss at $600-780^{\circ} \mathrm{C}$, and calculated by tangent method; $W$ is the total mass of the sample.

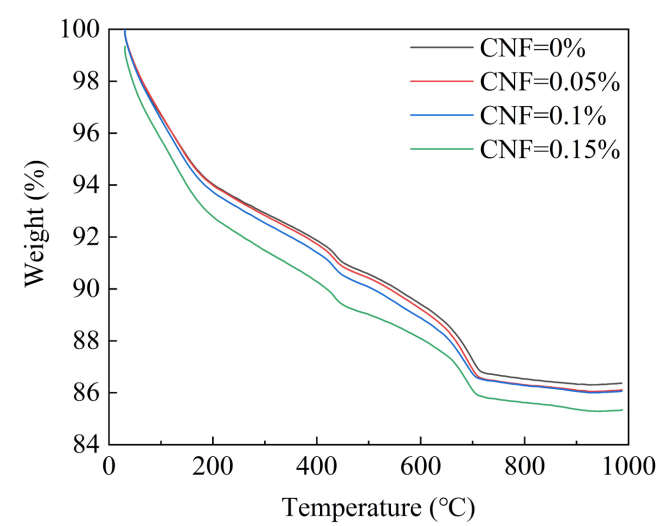

(a) TGA curves

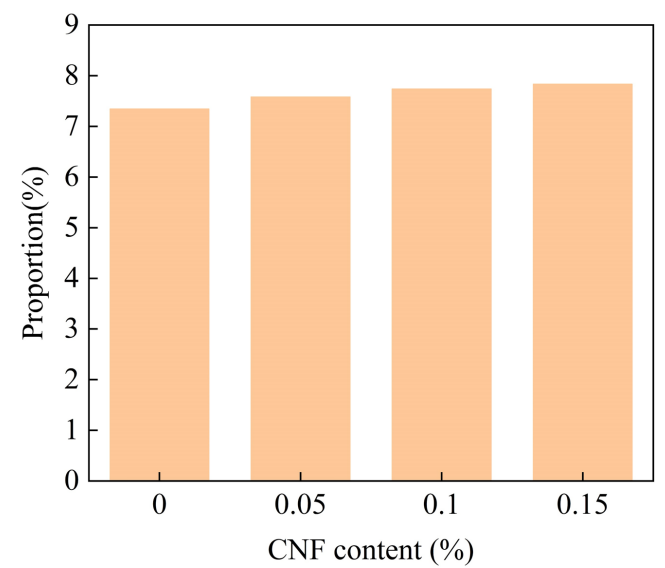

(b) CBW proportion

Fig. 6 Results of TGA with different CNF contents.

Fig. $6 \mathrm{~b}$ depicts the trend in the mass proportion of CBW with CNF. The increased values of CBW were observed in the samples with the CNF contents of $0.05 \%, 0.1 \%$, and $0.15 \%$, indicating that the DOH was promoted at 28 days due to the incorporation of CNF. These results confirmed to the mechanism of short circuit diffusion (SCD) by Cao (Cao et al. 2016a), meaning that CNF acted as channels to transport water to the unhydrated cement particle. Although CNF retarded the early age hydration (Section. 3.2), it led to higher DOH at 28 days.

\section{Rheology}

Both shear rate-shear stress upward and downward curves can be obtained by rheological tests. Herein, the rheological downward curves are selected for analysis, and the data obtained from the downward curves are considered to be more reliable and repeatable (Cappellari et al. 2013). The rheological downward curves of the refresh UHDCC matrices are presented in Fig. 7. After regression analysis by Origin software (OriginLab Corporation), the rheological curves of all groups conformed to the modified Bingham (MB) model equation, as Eq. (3).

$$
\tau=\tau_{0}+\mu \gamma+c \gamma^{2}
$$

where $\tau$ is the shear stress $(\mathrm{Pa}), \tau_{0}$ is the yield stress $(\mathrm{Pa}), \mu$ represents the plastic viscosity $(\mathrm{Pa} \cdot \mathrm{s}), \gamma$ stands for the shear rate $\left(\mathrm{s}^{-1}\right)$, and $c$ denotes the regression coefficient. 


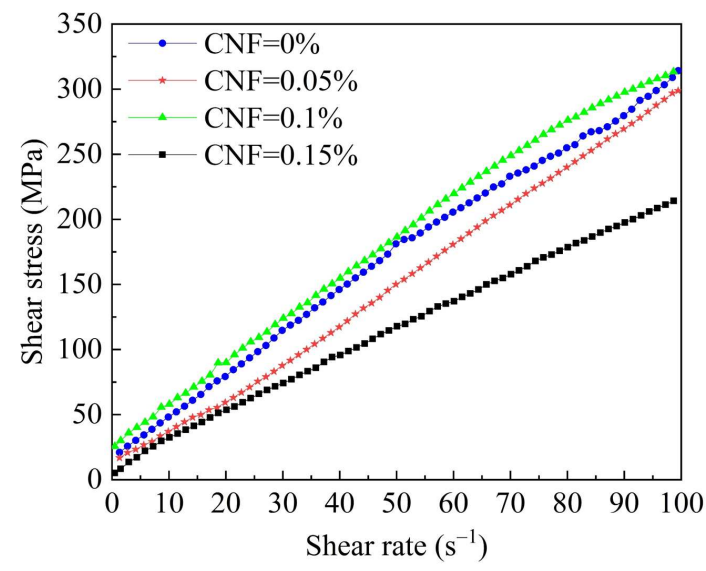

Fig. 7 Rheological curves of the refresh UHDCC matrix with different CNF contents.

The regression formulas and rheological parameters are listed in Table 5. The fitting correlation coefficients of all rheological curves were all above 0.99 , which indicates a relatively high correlation. It is evident that the MB model well fitted the experimental data. Therefore, it can be reasonably used to study the rheological properties of the fresh UHDCC matrices.

Table 5 Rheological parameters of the fresh ECC matrices.

\begin{tabular}{ccccc}
\hline CNF content $(\%)$ & Yield stress $(\mathrm{Pa})$ & $\begin{array}{c}\text { Plastic viscosity } \\
(\mathrm{Pa} \cdot \mathrm{s})\end{array}$ & Regression formula & $R^{2}$ \\
\hline 0 & 7.89 & 2.28 & $\tau=7.89+2.28 \gamma-0.00197 \gamma^{2}$ & 0.99976 \\
0.05 & 8.81 & 2.65 & $\tau=8.81+2.65 \gamma-0.00292 \gamma^{2}$ & 0.99927 \\
0.1 & 13.82 & 3.53 & $\tau=13.82+3.53 \gamma-0.006 \gamma^{2}$ & 0.99921 \\
0.15 & 21.35 & 3.65 & $\tau=21.35+3.65 \gamma-0.00641 \gamma^{2}$ & 0.99916 \\
\hline
\end{tabular}

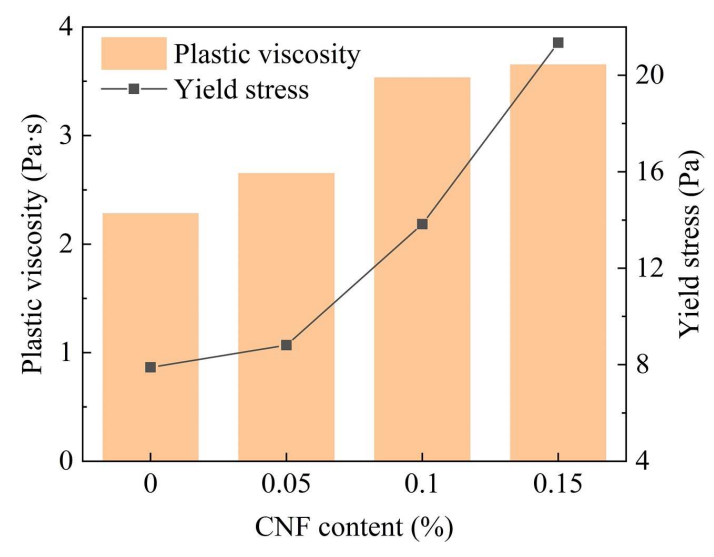

Fig. 8 Variation of yield stress and plastic viscosity of the fresh UHDCC matrices.

Fig. 8 displays the variations of the yield stress and plastic viscosity of the fresh UHDCC matrices with different CNF contents. Generally, the yield stress and plastic viscosity increased continuously as the CNF content rose. The CNF contents of $0.05 \%, 0.1 \%$, and $0.15 \%$ increased the plastic viscosity of the control group from 2.28 $\mathrm{Pa} \cdot \mathrm{s}$ to $2.65 \mathrm{~Pa} \cdot \mathrm{s}, 3.53 \mathrm{~Pa} \cdot \mathrm{s}$, and 3.65 $\mathrm{Pa} \cdot \mathrm{s}$. This corresponds to an increase in the yield stress from 7.89 Pa to $8.81 \mathrm{~Pa}, 13.83 \mathrm{~Pa}$, and $21.35 \mathrm{~Pa}$. CNF provides for the active surface with distinctive chemistries because of the hydroxyl and 
carboxylate groups on its surface. The surface of CNF can absorb the free water and reduce the effective water used for stirring mixtures, resulting in an increase in the friction between particles inside the mixtures (Montes et al. 2020). Besides, when CNF was added, the water requirement in the fresh matrices increased in the process of stirring, and then HRWR was needed to improve the flowability of the fresh matrices. Considering the influence of both HRWAR and CNF, it still appears that the addition of CNF had an obvious effect on the yield stress and plastic viscosity. The increase in the yield stress and plastic viscosity also explained a higher requirement in HRWR. As the CNF content rose from $0.05 \%$ to $0.1 \%$, the rheological parameters could undergo abrupt changes due to the formation of a CNF network (Hisseine et al. 2018a). For the case of UHDCC, the plastic viscosity of the fresh UHDCC matrices plays a crucial role in fiber dispersion (Yang et al. 2009). The tensile strain-hardening behavior of UHDCC is closely related to the uniformity of fiber dispersion, and excellent mechanical properties could be obtained by achieving uniform fiber dispersion (Sahmaran et al. 2013). Poor fiber dispersion will result in a reduced effective fiber volume fraction, which forms sections with weak bridging capacity, thereby leading to a lower tensile strain capacity ( $\mathrm{Li}$ and $\mathrm{Li} 2013$ ). The effect of the different plastic viscosity caused by the addition of CNF on the tensile properties will be discussed subsequently.

\section{Pore structure}

In general, MIP tests are conducted to determine the pore structure of cementitious materials composed of binders, water, and fine aggregates. However, the pore structure of the fiber reinforced cement-based materials (FRC), such as UHDCC, is vulnerable to fibers with a diameter at um level and a length at $\mathrm{mm}$ level, which could change the pore size distribution compared to matrices without fibers. As shown in Fig. 9(a), compared with UHDCC matrices, incorporating PE fibers enlarged the pore proportion of UHDCC ranged at 100-10000 nm and reduced that at 1-100 $\mathrm{nm}$. A major advantage of LF-NMR is that the direct correlation between the pore structure and mechanical properties of UHDCC can be established by the LF-NMR tests of unbroken specimens.

The addition of nanoparticles is considered to be an effective method for enhancing the pore structure of cementitious composites (Ghafari et al. 2015). Pores are classified on the basis of the pore radius (Kumar and Bhattacharjee 2003) as gel pores $(0.5 \mathrm{~nm}<$ radius $<10 \mathrm{~nm}$ ), fine capillary pores $(10-50 \mathrm{~nm})$, large capillary pores $(50-5000 \mathrm{~nm})$, and non-capillary pores (radius $>5000 \mathrm{~nm}$ ). The pore size distribution and pore volume fraction are plotted in Fig. 9. The values for the total porosity of UHDCC matrices containing $0 \%, 0.05 \%, 0.1 \%$, and $0.15 \%$ CNF were $8.69 \%, 8.76 \%$, $8.09 \%$ and $7.82 \%$, respectively, and corresponding values of ECC were $11.5 \%, 10.87 \%, 10.64 \%$ and $8.41 \%$, respectively. The CNF content of $0.15 \%$ significantly decreased the total porosity of matrices and UHDCC. As observed from Fig. 9a, the addition of CNF reduced a large proportion of pore size and refined the pore size distribution. In addition, CNF failed to change the most probable pore radius, and all groups shared a constant value of around $13.73 \mathrm{~nm}$. Fig. $9 \mathrm{~b}$ illustrates the pore volume distribution. As the CNF content increased from $0 \%$ to $0.15 \%$, various pores were refined. Some harmful pore (> $50 \mathrm{~nm}$ ) (Zhang et al. 2020a) was reduced due to the addition of $\mathrm{CNF}$, which is favorable for the improvement of mechanical properties and durability. 

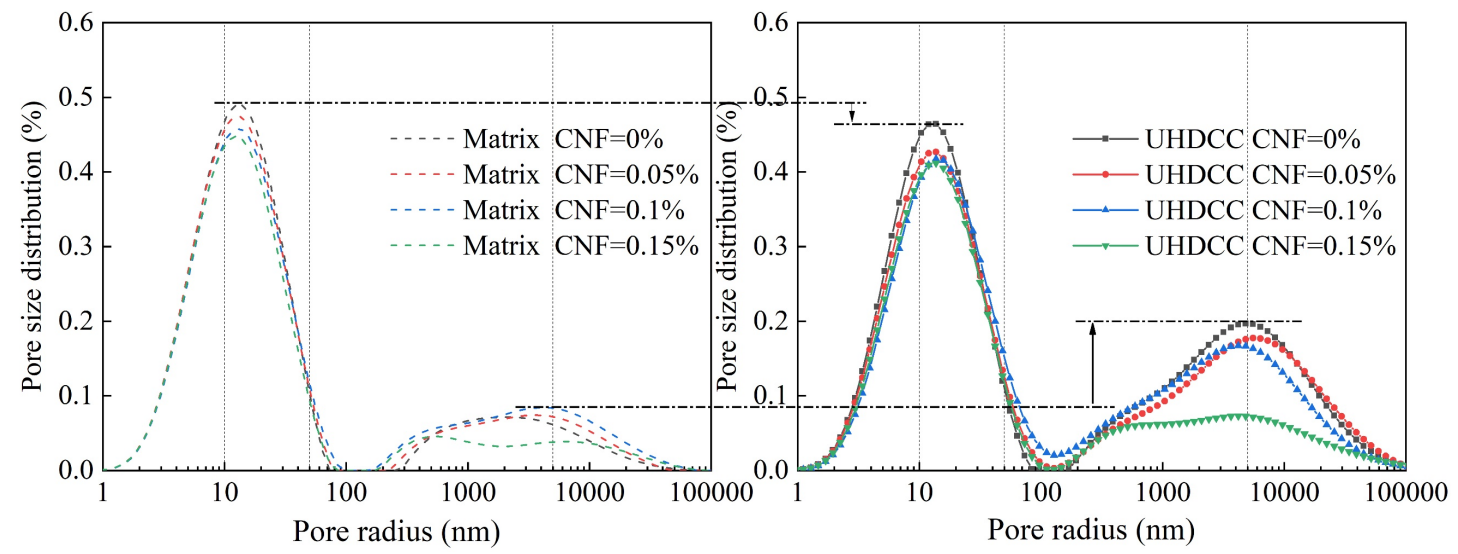

(a) Pore size distribution of matrices and UHDCC

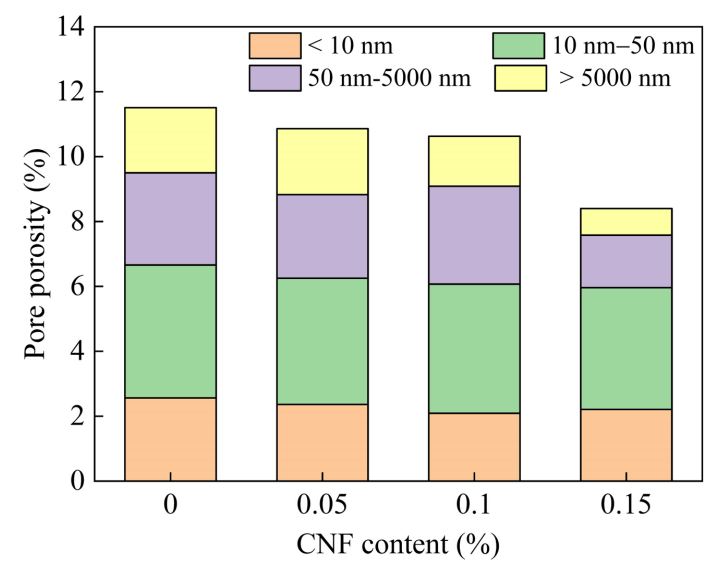

(b) Pore volume fraction of UHDCC

Fig. 9 Effect of CNF on the pore structure

\section{Compressive strength}

The effect of CNF on the compressive strength of UHDCC at 28 days is presented in Fig. 10. The compressive strength of UHDCC without CNF was only $53.6 \mathrm{MPa}$, and the addition of CNF significantly enhanced the compressive strength of UHDCC. When CNF with the contents of $0.05 \%, 0.1 \%$, and $0.15 \%$ was added, the compressive strength was $58.4 \mathrm{MPa}, 64.4 \mathrm{MPa}$, and 78.3 $\mathrm{MPa}$, respectively, indicating an increase of $8.9 \%, 20.1 \%$, and $46.1 \%$, respectively. The total porosity of UHDCC decreased with the increasing CNF contents, which could increase the compactness of UHDCC as mentioned in Section 3.4., and then enhance its compressive strength. 


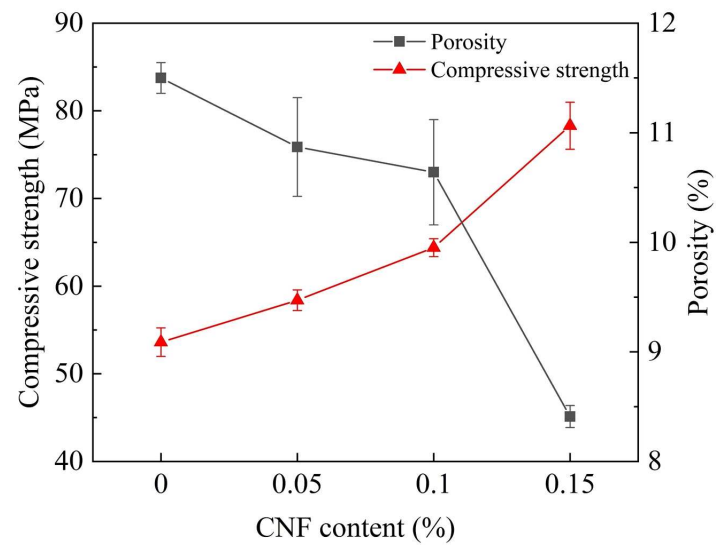

Fig. 10 The compressive strength of UHDCC with different CNF contents.

\section{Tensile properties}

\section{Tensile parameters}

The uniaxial tensile stress-strain curves of UHDCC at various CNF contents are delineated in Fig. 11, and all specimens exhibited obvious tensile strain-hardening behavior. The initial cracking strength $\left(\sigma_{\mathrm{tc}}\right)$, the ultimate tensile strength $\left(\sigma_{\mathrm{tp}}\right)$, and the tensile strain $\left(\varepsilon_{\mathrm{tu}}\right)$, and strain energy $\left(g_{\mathrm{se}}\right)$ were used to characterize the tensile behavior capacity of UHDCC. The crack numbers $\left(n_{\mathrm{c}}\right)$, the crack width $\left(w_{\mathrm{c}}\right)$, and the crack spacing $\left(d_{\mathrm{c}}\right)$ were calculated to characterize the feature of multiple cracks. The crucial tensile parameters above motioned are tabulated in table 6 .

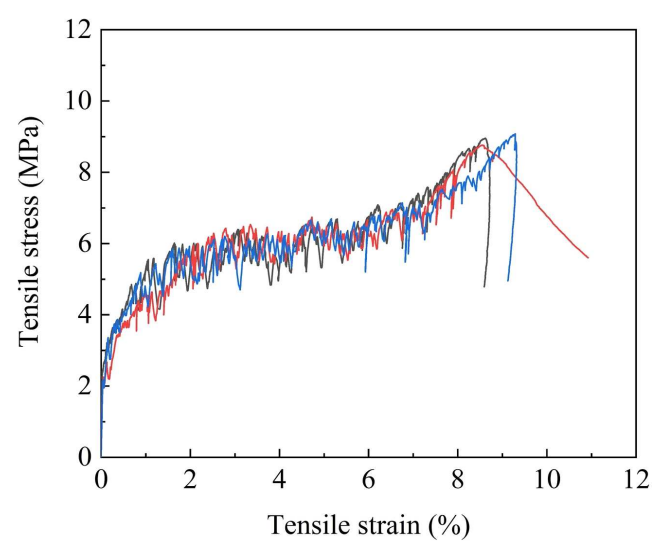

(a) $\mathrm{CNF}=0 \%$

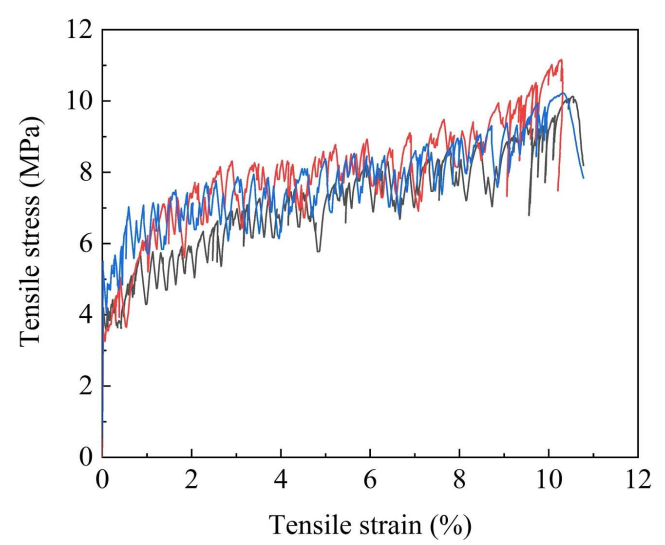

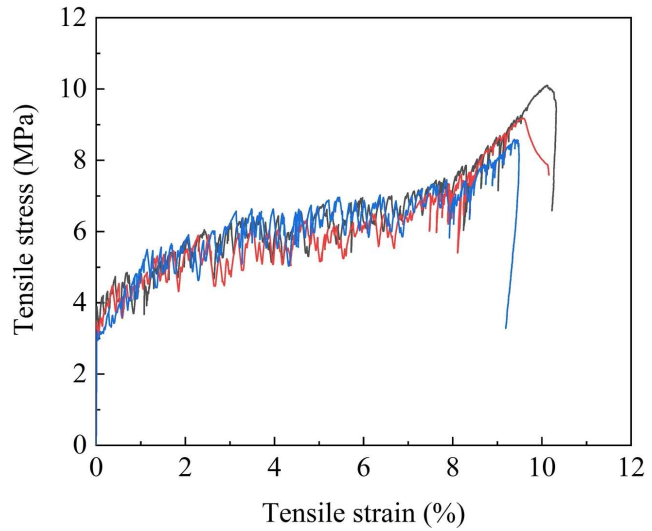

(b) $\mathrm{CNF}=0.05 \%$

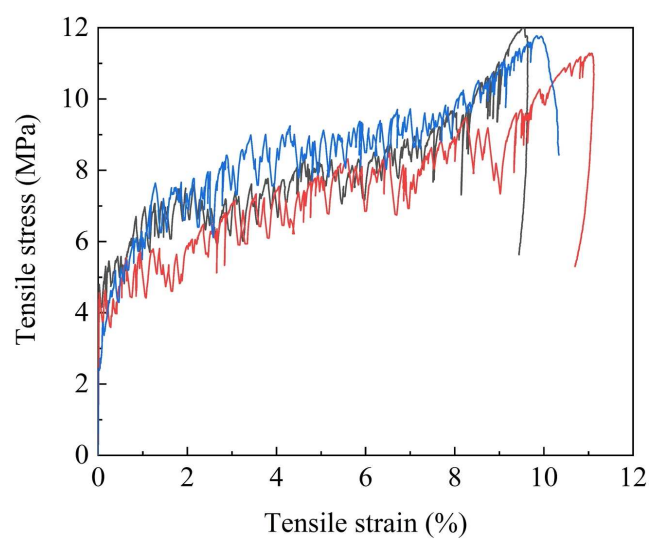



(c) $\mathrm{CNF}=0.1 \%$
(d) $\mathrm{CNF}=0.15 \%$

Fig. 11 Tensile stress-strain curves of ECC with different CNF contents.

Table 6 Tensile parameters of UHDCC with different CNF contents.

\begin{tabular}{cccccccc}
\hline CNF content $(\%)$ & $\sigma_{\mathrm{tc}}(\mathrm{MPa})$ & $\sigma_{\mathrm{tp}}(\mathrm{MPa})$ & $\mathcal{E}_{\mathrm{tu}}(\%)$ & $g_{\mathrm{se}}\left(\mathrm{kJ} / \mathrm{m}^{3}\right)$ & $n_{\mathrm{c}}$ & $w_{\mathrm{c}}(\mu \mathrm{m})$ & $d_{\mathrm{c}}(\mathrm{mm})$ \\
\hline 0 & $2.28 \pm 0.10$ & $8.93 \pm 0.13$ & $8.82 \pm 0.33$ & $534 \pm 26$ & $59 \pm 4$ & $121.2 \pm 11.6$ & $1.49 \pm 0.11$ \\
0.05 & $3.53 \pm 0.28$ & $9.29 \pm 0.62$ & $9.69 \pm 0.30$ & $596 \pm 36$ & $70 \pm 7$ & $111.1 \pm 8.5$ & $1.26 \pm 0.13$ \\
0.1 & $4.41 \pm 0.80$ & $10.50 \pm 0.47$ & $10.39 \pm 0.11$ & $783 \pm 27$ & $63 \pm 7$ & $133.9 \pm 17.8$ & $1.42 \pm 0.17$ \\
& & & & & & & \\
0.15 & $4.36 \pm 0.46$ & $11.68 \pm 0.30$ & $10.14 \pm 0.64$ & $797 \pm 36$ & $56 \pm 3$ & $145.7 \pm 16.9$ & $1.58 \pm 0.09$ \\
\hline
\end{tabular}

Fig. 12 summarizes the comparison of the tensile parameters of UHDCC with different CNF contents. Fig. 12a showed that the initial cracking stress increased from $2.28 \mathrm{MPa}$ to $3.53 \mathrm{MPa}$, 4.41 MPa, and 4.36 MPa by $54.8 \%, 93.4 \%$, and $91.2 \%$ when the content of CNF increased from $0 \%$ to $0.15 \%$. The initial cracking stress of UHDCC is mainly determined by matrices (Ma et al. 2017). The rise in the initial cracking stress could be attributed to the increase in the compactness, and the role of CNF with fibrils-shaped in bridging the initial flaws of matrices at a microscopic level. The peak stress increased monotonically from $8.93 \mathrm{MPa}$ for $0 \% \mathrm{CNF}$ to $11.68 \mathrm{MPa}$ for $0.15 \%$ CNF with a $30.8 \%$ increase. Higher compactness of ECC could form stronger frictional bonding between matrices and fibers, which could further increase the peak stress of UHDCC. Additionally, the enhancement of initial cracking stress was more obvious than that of the peak stress.

As shown in Fig. 12b, the tensile strain of UHDCC with the incorporation of $0-0.15 \% \mathrm{CNF}$ all exceeded $8 \%$. With a slight increase in the CNF content from $0 \%$ to $0.05 \%$, the tensile strain increased from $8.82 \%$ to $9.69 \%$. Considering the crack number and crack width in Fig. 12c, the crack number increased from 59 to 70 , leading to a decrease in the crack width from $121.2 \mu \mathrm{m}$ to $111.1 \mu \mathrm{m}$. When the CNF content further increased from $0.05 \%$ to $0.1 \%$ and $0.15 \%$, the tensile strain continued to increase to $10.39 \%$ and $10.14 \%$. However, the crack number dropped to the values close to the UHDCC without CNF, and the crack width increased to $133.9 \mu \mathrm{m}$ and 145.7 $\mu \mathrm{m}$. The typical crack patterns of UHDCC with different CNF contents are shown in Fig. 13. The average crack width of all groups was less than $150 \mu \mathrm{m}$, which exhibits the excellent ability in controlling crack propagation. As mentioned in 3.1, the plastic viscosity with the CNF contents of $0 \%, 0.05 \%, 0.1 \%$, and $0.15 \%$ was $2.28 \mathrm{~Pa} \cdot \mathrm{s}, 2.65 \mathrm{~Pa} \cdot \mathrm{s}, 3.53 \mathrm{~Pa} \cdot \mathrm{s}$, and $3.65 \mathrm{~Pa} \cdot \mathrm{s}$, respectively. With the CNF contents of $0.05 \%$ and $0.1 \%$, a more saturated multiple cracking behavior that led to more cracks might be attributed to the increase in the plastic viscosity, resulting in the more uniform dispersion of fibers. When the CNF content further increased to $0.15 \%$, the higher value of the viscosity plastic was adverse, leading to the uneven dispersion of fibers. Furthermore, Fig. 12d illustrates the effect of CNF on the tensile strain energy, showing a monotonically increasing trend. The tensile strain energy raised continuously from $534 \mathrm{~kJ} / \mathrm{m}^{3}$ to $797 \mathrm{~kJ} / \mathrm{m}^{3}$ when the CNF content increased from $0 \%$ to $0.15 \%$. 


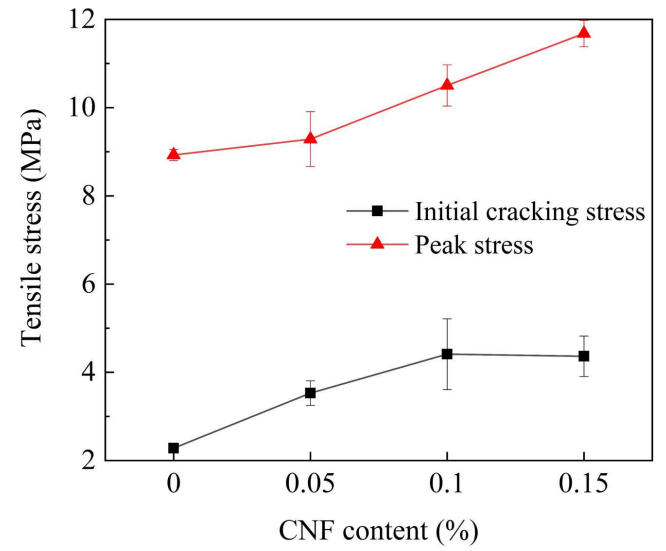

(a) Initial cracking stress and peak stress

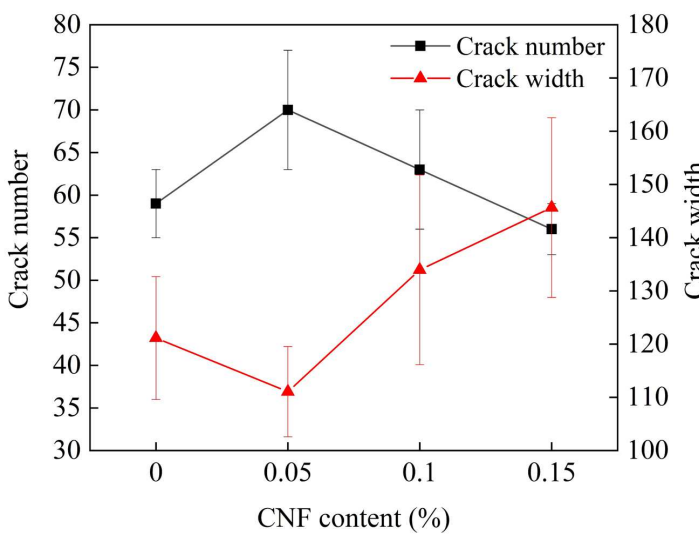

(c) Crack number and crack width

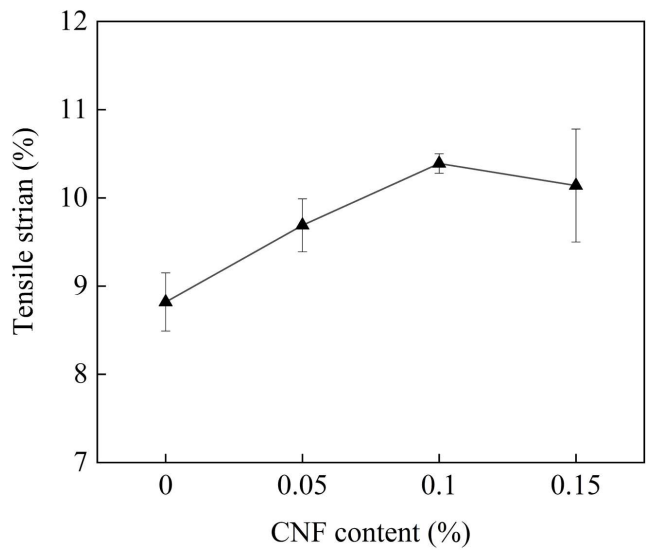

(b) Tensile strain

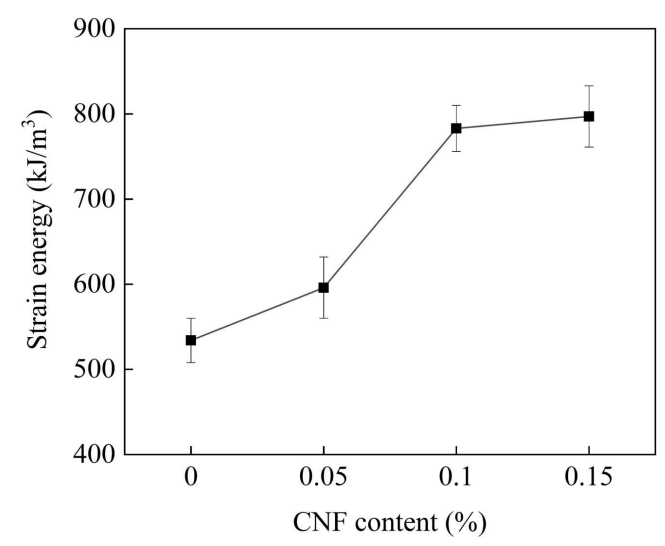

(d) Strain energy

Fig. 12 Comparison of tensile parameters of UHDCC with different CNF contents.

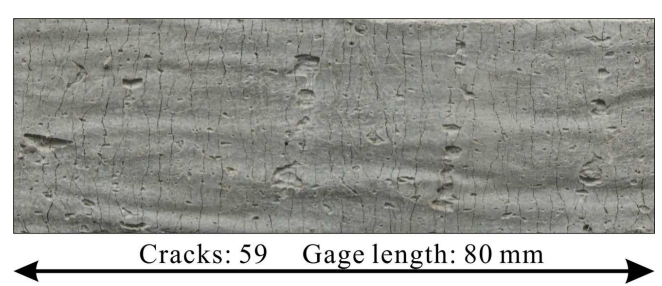

(a) $\mathrm{CNF}=0 \%$

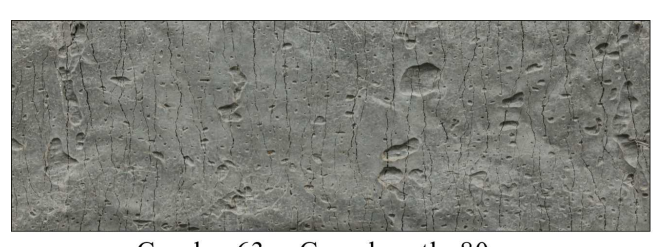

Cracks: 63 Gage length: $80 \mathrm{~mm}$

(c) $\mathrm{CNF}=0.1 \%$

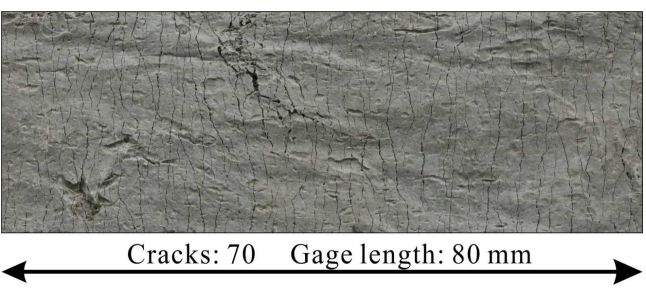

(b) $\mathrm{CNF}=0.05 \%$

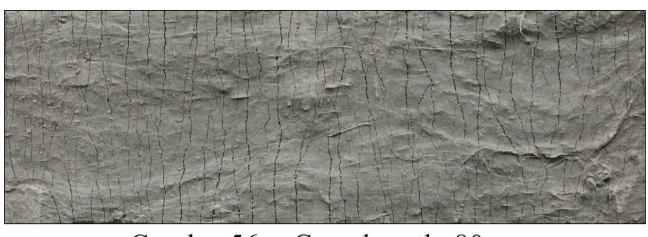

Cracks: 56 Gage length: $80 \mathrm{~mm}$

(d) $\mathrm{CNF}=0.15 \%$

Fig. 13 Typical crack patterns of UHDCC with different CNF contents.

\section{Interpretation of high ductility}

The tensile strain capacity is considered to be the most important index of UHDCC. Under 
uniaxial tensile conditions, all specimens presented a strain-hardening behavior to varying degrees, which is caused by the cracking of matrices, the debonding and rupture process of fibers, and the propagation of cracks. In the microscopic design of pseudo-strain hardening, an energy criterion should be satisfied to ensure a cracking mode, as expressed in Eq. (4):

$$
J_{t i p}=\frac{K_{m}^{2}}{E_{m}} \leq J_{b}^{\prime}=\sigma_{0} \delta_{0}-\int_{0}^{\delta_{0}} \sigma(\delta) d \delta
$$

where $J_{b}^{\prime}$ is the fiber bridging complementary energy, $J_{t i p}$ represents the crack tip toughness, $\sigma_{0}$ stands for the maximum stress, $\delta_{0}$ indicates cracking opening displacement corresponding to $\sigma_{0}, K_{m}$ is the matrix fracture toughness, and $E_{m}$ stands for the tensile elastic modulus of UHDCC. $K_{m}$ is calculated according to the reference (Xu and Reinhardt 2000). $J_{b}^{\prime}$ is calculated by the integral approach in $\sigma-\delta$ curves obtained by the single-crack tensile test, as illustrated in Fig. 14.

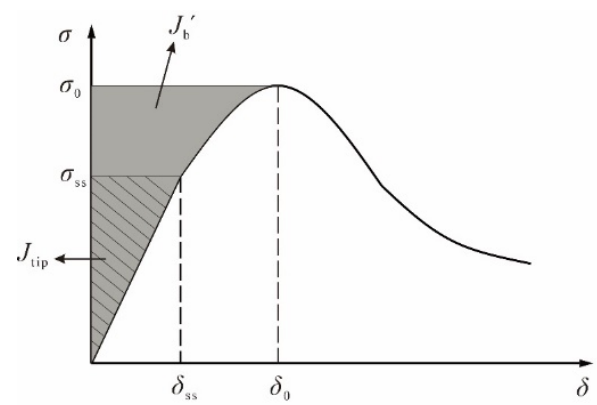

Fig. 14 Typical $\sigma-\delta$ curve for UHDCC.

Table 7 lists the values of $J_{b}^{\prime}$ and $J_{t i p}$, and $P S H_{\mathrm{e}}$ is further determined. As shown in Table 7, the value of $J_{b}^{\prime}$ was enhanced continuously with increasing CNF contents, and the enhancement in the value of $J_{t i p}$ was less than $J_{b}^{\prime}$. Thus, the value of $P S H_{\mathrm{e}}\left(J_{b}^{\prime} / J_{t i p}\right)$ could be enlarged, improving the tensile strain capacity. Fig. 15 depicts a similar trend with $P S H_{\mathrm{e}}$ and $\varepsilon_{\mathrm{u}}$ with different CNF contents.

Table 7 Results of single-crack tensile test and notched three-point bending test.

\begin{tabular}{cccccc}
\hline CNF content $(\%)$ & $K_{\mathrm{m}}\left(\mathrm{MPa} \cdot \mathrm{m}^{1 / 2}\right)$ & $J_{\text {tip }}\left(\mathrm{J} / \mathrm{m}^{2}\right)$ & $J_{\mathrm{b}}{ }^{\prime}\left(\mathrm{J} / \mathrm{m}^{2}\right)$ & $J_{\mathrm{b}} / J_{\text {tip }}$ & $\varepsilon_{\text {tu }}(\%)$ \\
\hline 0 & $0.494 \pm 0.048$ & $14.42 \pm 3.18$ & 2208.80 & 153.18 & $8.82 \pm 0.33$ \\
0.05 & $0.567 \pm 0.018$ & $13.75 \pm 0.33$ & 2395.53 & 174.22 & $9.69 \pm 0.30$ \\
0.1 & $0.594 \pm 0.052$ & $16.10 \pm 3.18$ & 2972.87 & 184.65 & $10.39 \pm 0.11$ \\
0.15 & $0.655 \pm 0.035$ & $17.80 \pm 5.84$ & 3041.66 & 170.88 & $10.14 \pm 0.64$ \\
\hline
\end{tabular}




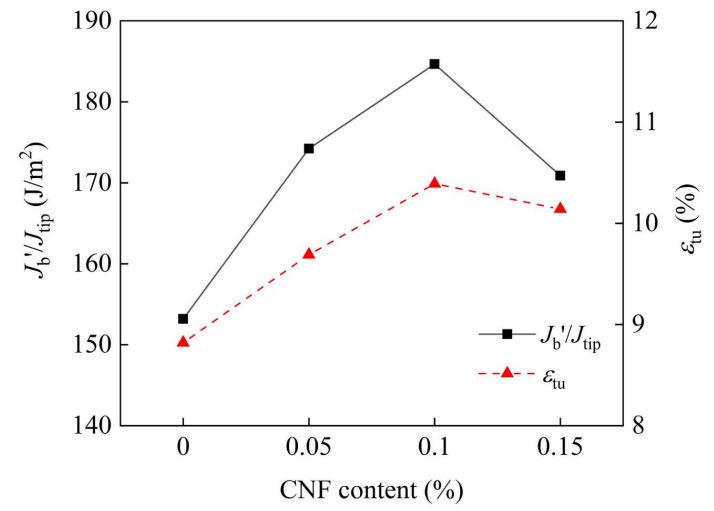

Fig. 15 Trends of $J_{\mathrm{b}} / J_{\text {tip }}$ and $\varepsilon_{\text {tu }}$ with the increase in CNF contents.

\section{Flexural properties}

Fig. 16 presents the flexural stress-deflection span ratio curves of UHDCC with different CNF contents, characterizing by the bend deflection-hardening behavior and indicating the excellent bend ductility. Fig. 17 shows the variation of flexural initial cracking stress and peak stress with different CNF contents. The blank group ( $0 \% \mathrm{CNF}$ ) exhibits the initial cracking stress of $6.81 \mathrm{MPa}$, and the addition of $\mathrm{CNF}$ at $0.05 \%, 0.1 \%$, and $0.15 \%$ content leads to that of $7.2 \mathrm{MPa}, 8.2 \mathrm{MPa}$, and $10.53 \mathrm{MPa}$, respectively. This corresponds to the enhancement of initial cracking stress by $5.7 \%, 20.4 \%$, and $54.6 \%$, respectively. The addition of $0.1 \%$ CNF significantly improved the peak stress from $22.93 \mathrm{MPa}$ to $26.33 \mathrm{MPa}$ by $14.8 \%$. The maximum value of the ultimate deflection span ratio appeared at the CNF content of $0.05 \%$, then for subsequent CNF contents of $0.15 \%$ and $0.1 \%$.

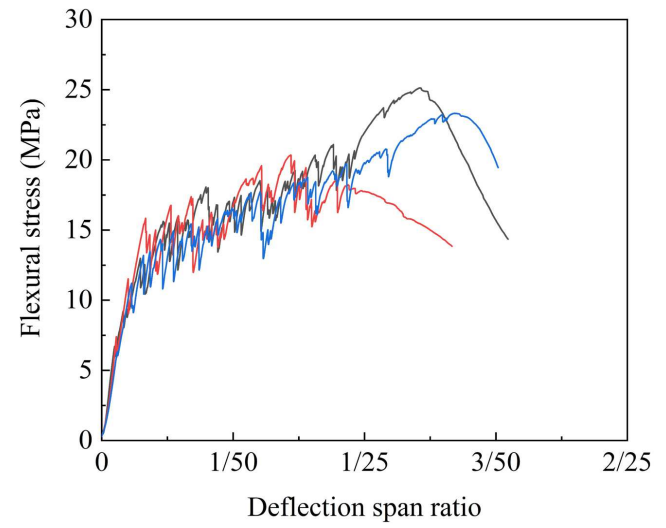

(a) $\mathrm{CNF}=0 \%$

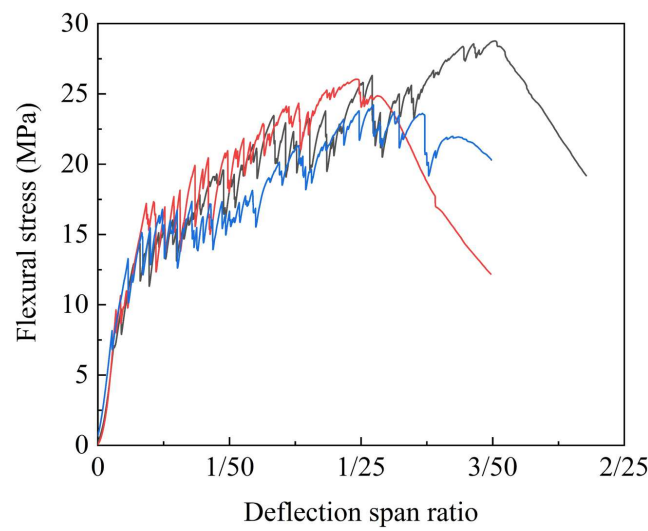

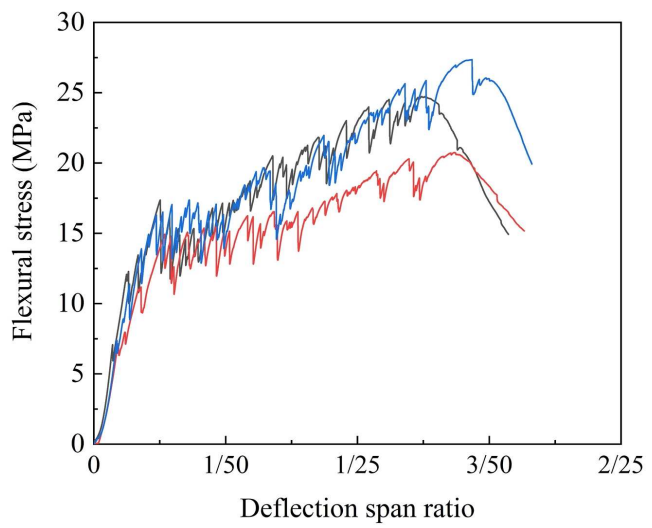

(b) $\mathrm{CNF}=0.05 \%$

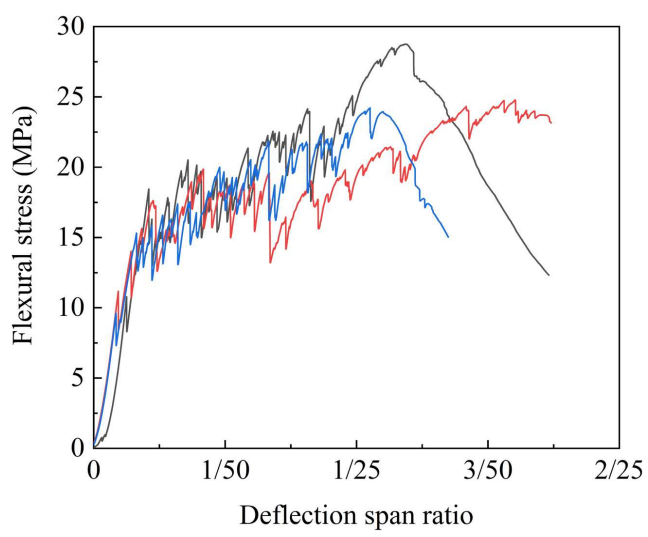


Fig. 16 Flexural stress-deflection span ratio curves of UHDCC with different CNF contents.

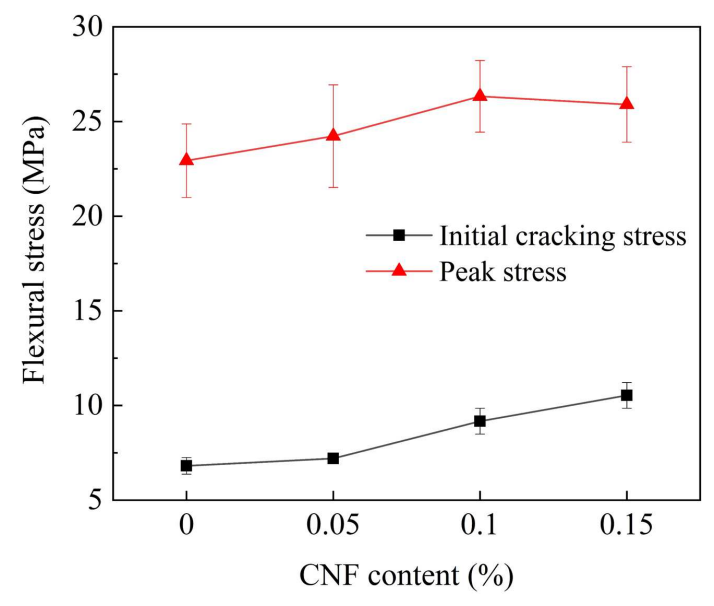

Fig. 17 Flexural stress-deflection span ratio curves of UHDCC with different CNF contents.

\section{Discussion}

Based on the results from this study, it is proved that CNF plays a role in improving the multiscale properties of UHDCC. Fig. 18 summarizes the mechanism for the improved mechanical properties of CNF reinforced UHDCC. Firstly, owing to the absorption of CNF on the surface of cement particles, adding CNF in UHDCC matrices led to the retardation of the hydration heat release before $70 \mathrm{~h}$. With the continuation of the hydration reaction, CNF as the channel could transport water into the unhydrated cement core to accelerate the hydration, and thus DOH was enhanced at 28 days. Then, the pore structure of UHDCC was refined, and the harmful pores were reduced, leading to a higher compressive strength. Under the condition of loads, when the initial flaws (micro-cracks) of the weakest cross-section of matrices tended to expand, CNF might bridge the initial flaws due to its high aspect ratio. After appearing macro-cracks in UHDCC, PE fibers could suppress the propagation of a single crack, and then trigger the generation of multiple cracks. $\mathrm{CNF}$ and PE fibers allowed the cracking resistance at multiple scales. At the time of designing UHDCC, the rheological properties of the fresh UHDCC matrices should be considered and combined with the micromechanics theory, and an optimal range of the plastic viscosity should be found for reaching uniform fiber dispersion. ( $\mathrm{Li}$ and $\mathrm{Li} 2013$ ). According to the results from Section. 3.1, The addition of CNF could modify the plastic viscosity of the fresh UHDCC matrices. The tensile test results from Section. 3. 4 proved that all specimens for four groups with the plastic viscosity of 2.28-3.65 Pa.s exhibited ultra-high tensile ductility, which indicates that the viscosity range of 2.28-3.65 $\mathrm{Pa} \cdot \mathrm{s}$ was favorable to the dispersion of PE fibers. Therefore, it may be feasible that using CNF as a viscosity modifying agent (VMA) develops UHDCC. Meanwhile, the high viscosity system of UHDCC matrices might contribute to the mutual promotion of dispersion between PE fiber and CNF. Fig. 19a shows the status of the pulled-out fiber surface for $0 \% \mathrm{CNF}$ content, while Fig. 19b shows that fiber surfaces were scratched and rough when the CNF content was $0.1 \%$, which was attributed to the higher compactness of UHDCC. The effective results from the mechanical tests reflect the CNF content of $0.05-0.15 \%$ remained a positive effect on the properties of UHDCC, which demonstrates partly a good dispersion of CNF into UHDCC. 

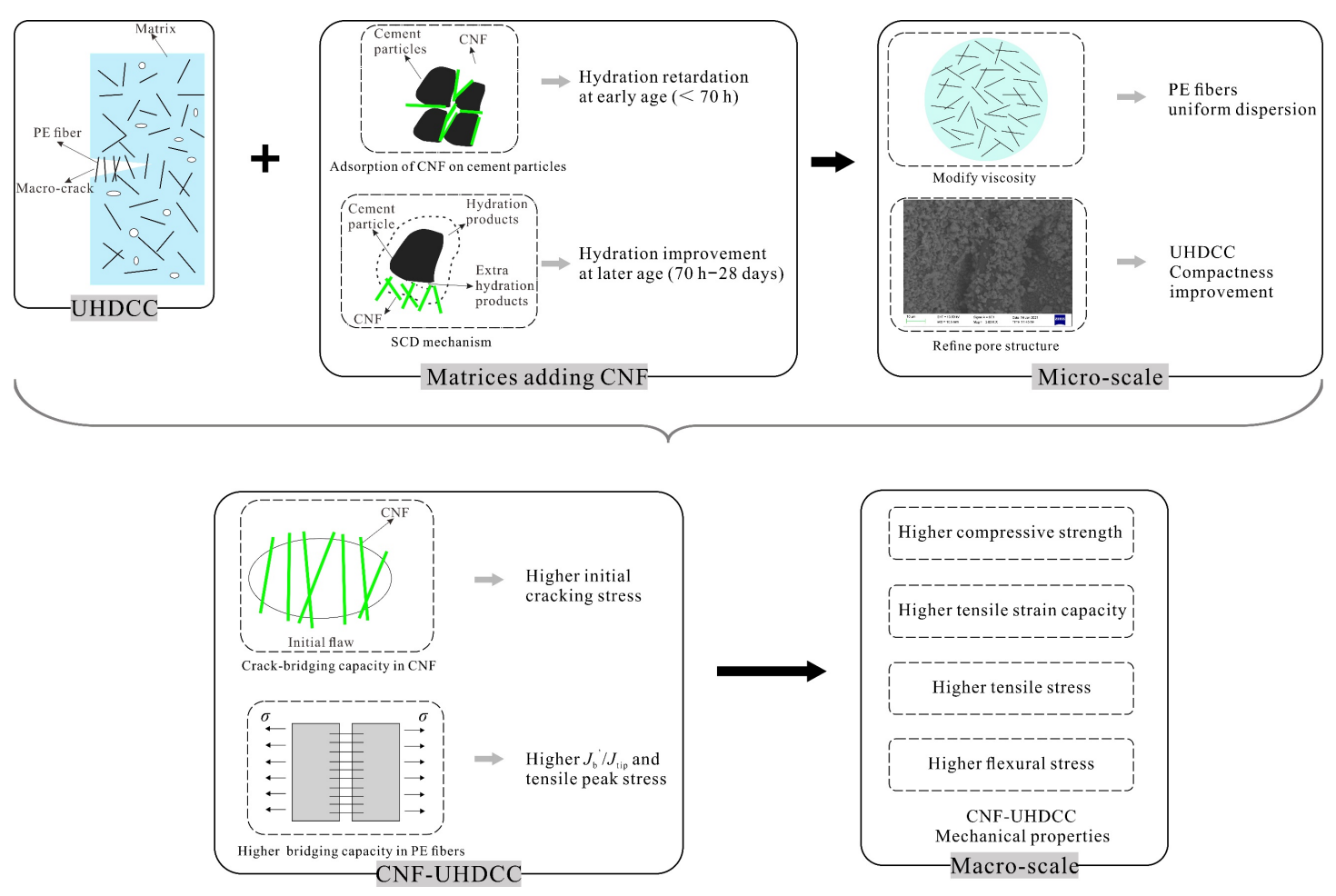

Fig. 18 Schematic of the effects of CNF on UHDCC.

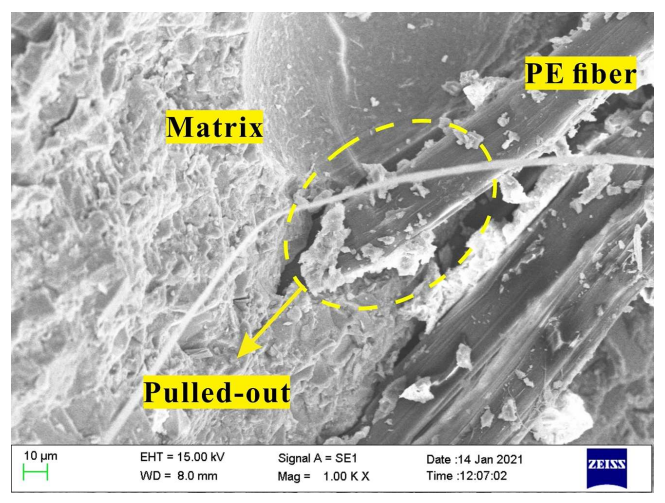

(a) UHDCC with $0 \% \mathrm{CNF}$ content

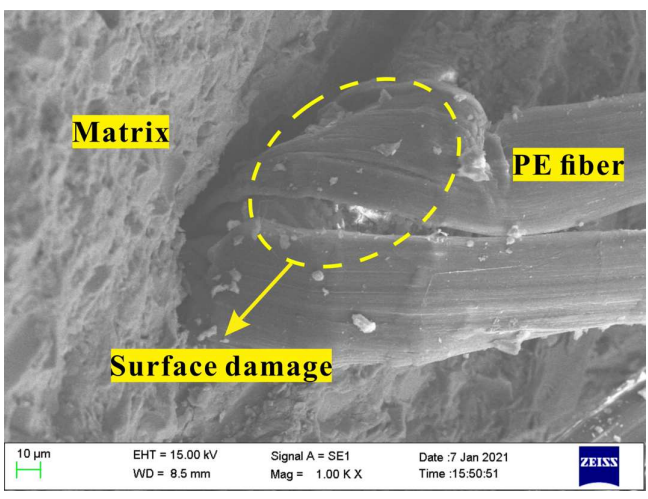

(b) UHDCC with $0.1 \%$ CNF content

Fig. 19 SEM images of PE fiber surfaces.

Table 8 summarizes the degree of improvement of various nanomaterials on the mechanical properties of UHDCC in the previous studies. It can be noted that the CNF content of a mere $0.1 \%$ in this study could result in the improvement on the compressive strength of $+20.1 \%$, tensile stress of $+17.6 \%$, and tensile strain of $+17.8 \%$. Under the condition of developing ECC, the role of CNF appears to be similar to that of VMA based on cellulose ether, which is to adjust the viscosity of the fresh UHDCC matrices. The difference between VMA and CNF might be that CNF has the potential to be a reinforcing agent. Compared with other nanomaterials, CNF presents a more promising capacity in modifying the basic mechanical performances of UHDCC.

Table 8 Effect of various nano-particles on the mechanical properties of UHDCC.

\begin{tabular}{cccccc}
\hline \multirow{2}{*}{ References } & Type & $\begin{array}{c}\text { Content of } \\
\text { nanomaterial }\end{array}$ & $\begin{array}{c}\text { Compressive } \\
\text { strength }\end{array}$ & $\begin{array}{c}\text { Tensile } \\
\text { stress }\end{array}$ & $\begin{array}{c}\text { Tensile } \\
\text { strain }\end{array}$ \\
\hline $\begin{array}{c}\text { Ding et al. } \\
\begin{array}{c}\text { (Ding et al. } \\
\text { 2020) }\end{array}\end{array}$ & PE-UHDCC & NC 3\% & $+7.7 \%$ & $+39.6 \%$ & $+10.3 \%$
\end{tabular}




\begin{tabular}{|c|c|c|c|c|c|}
\hline $\begin{array}{l}\text { Xi et al. (Xi et } \\
\text { al. 2020) }\end{array}$ & PE-UHDCC & NS $2 \%$ & $+16.7 \%$ & $+59.4 \%$ & $+15.9 \%$ \\
\hline $\begin{array}{l}\text { Ding et al. } \\
\text { (Ding et al. } \\
\text { 2021) }\end{array}$ & PE-UHDCC & NS $2 \%$ & $+16.2 \%$ & $+18.8 \%$ & $-29.4 \%$ \\
\hline $\begin{array}{l}\text { Li et al. ( } \mathrm{Li} \text { et } \\
\quad \text { al. 2016) }\end{array}$ & $\begin{array}{l}\text { Hybrid- } \\
\text { UHDCC }\end{array}$ & NS 3\% & l & $+20.1 \%$ & $-3.38 \%$ \\
\hline $\begin{array}{l}\text { Xu et al. (Xu } \\
\text { et al. 2019) }\end{array}$ & $\begin{array}{l}\text { Hybrid- } \\
\text { UHDCC }\end{array}$ & MWCNT $0.1 \%$ & $+18 \%$ & $+41.7 \%$ & $+16 \%$ \\
\hline $\begin{array}{l}\text { Yu et al. (Yu } \\
\text { et al. 2020) }\end{array}$ & PVA-ECC & NS $1.5 \%$ & $+55 \%$ & / & l \\
\hline $\begin{array}{l}\text { Lu et al. (Lu } \\
\text { et al. 2016) }\end{array}$ & PVA-ECC & GO $0.08 \%$ & $+24.8 \%$ & $+37.7 \%$ & $+18.8 \%$ \\
\hline This study & $\begin{array}{c}\text { PE- } \\
\text { UHDCC }\end{array}$ & CNF $0.05 \%$ & $+8.9 \%$ & $+4.0 \%$ & $+9.9 \%$ \\
\hline This study & $\begin{array}{c}\text { PE- } \\
\text { UHDCC }\end{array}$ & CNF $0.1 \%$ & $+20.1 \%$ & $+17.6 \%$ & $+17.8 \%$ \\
\hline This study & $\begin{array}{c}\text { PE- } \\
\text { UHDCC }\end{array}$ & CNF $0.1 \%$ & $+46.1 \%$ & $+30.8 \%$ & $+15.0 \%$ \\
\hline
\end{tabular}

Notes: NC: nano- $\mathrm{CaCO}_{3}$; NS: nano- $\mathrm{SiO}_{2}$; MWCNT: multi-walled carbon nanotube; GO: graphene oxide. + increased; -: decreased; /: not reported.

\section{Conclusions}

This work investigated the application of nanofibrillated cellulose (CNF), a green renewable nanomaterial, in the preparation of UHDCC. To this end, a series of systematic analyses were conducted to study the effect of CNF on the rheology, microstructure, and mechanical properties of UHDCC. The following conclusions can be drawn from the findings of this work:

(1) CNF showed retardation on the peak of UHDCC matrix hydration heat flow at early ages, and an increase in the heat release occurred at $70 \mathrm{~h}$ for $0.05 \% \mathrm{CNF}$ and $110 \mathrm{~h}$ for $0.1 \% \mathrm{CNF}$. However, $0.05-0.15 \%$ of CNF increased the hydration degree of cement at 28 days.

(2) The addition of CNF had an obvious effect on the yield stress and plastic viscosity of the fresh UHDCC matrices, and CNF could be used as a viscosity-enhancing admixture to adjust the rheological parameters.

(3) LF-NMR analysis confirmed that the addition of CNF effectively reduced the total porosity of UHDCC and refined its pore size distribution, enhancing its compactness. Therefore, the compressive strength of UHDCC significantly improved with increasing CNF contents. At the CNF content of $0 \%, 0.05 \%, 0.1 \%$, and $0.15 \%$, the compressive strength increased of UHDCC by $8.9 \%, 20.1 \%$, and $46.1 \%$, respectively.

(4) Raising the CNF content from $0 \%$ to $0.15 \%$ enhanced the tensile peak stress of UHDCC up to $30.8 \%$, and the $0.1 \% \mathrm{CNF}$ lead to the maximum initial cracking stress with an increase of $94.3 \%$. The tensile strain of UHDCC with $0-0.15 \% \mathrm{CNF}$ all exceeded $8 \%$. The corresponding tensile strain energy increased steadily from $534 \mathrm{~kJ} / \mathrm{m}^{3}$ to $797 \mathrm{~kJ} / \mathrm{m}^{3}$. Likewise, the effect of CNF on flexural properties resembled tensile properties.

(5) $0.05 \% \mathrm{CNF}$ would be regarded as an optimal content to pursue mainly higher ductility and lower crack width, and the strength could be enhanced slightly. To achieve higher compressive strength, tensile peak stress, tensile strain, strain energy, and flexural stress, the CNF content of $0.1-0.15 \%$ could be selected, whereas the crack width could be enlarged marginally (still controlled less than $150 \mathrm{~mm}$ ). 


\section{Conflict of interest}

We declare that we do not have any competing commercial interests or personal relationships in the submitted work.

\section{Acknowledgments}

This work was supported by the National Natural Science Foundation of China with Grant (No. 52038006 and 52078282), the China Academy of Engineering Consulting Project "Research on Development Strategy and Key Technologies of Bamboo Construction Sector in China towards 2035" (No. 2018-ZCQ-06) and the Program for Changjiang Scholars and Innovative Research Team from the University of China (grant number IRT_17R69). The research into the pore structure was performed at Suzhou Niumag Analytical Instrument Corporation, Jiangsu, China for providing LF-NMR analysis. We are also grateful to Papergoing (www.papergoing.com) for its linguistic assistance during the preparation of this manuscript.

\section{References}

Barnat-Hunek D, Szymańska-Chargot M, Jarosz-Hadam M, Łagód G (2019) Effect of cellulose nanofibrils and nanocrystals on physical properties of concrete. Constr Build Mater 223:1-11 Bede A, Scurtu A, Ardelean I (2016) NMR relaxation of molecules confined inside the cement paste pores under partially saturated conditions. Cem Concr Res 89:56-62

Cao Y, Tian N, Bahr D, et al (2016a) The influence of cellulose nanocrystals on the microstructure of cement paste. Cem Concr Compos 74:164-173

Cao Y, Zavaterri P, Youngblood J, et al (2015) The influence of cellulose nanocrystal additions on the performance of cement paste. Cem Concr Compos 56:73-83

Cao Y, Zavattieri P, Youngblood J, et al (2016b) The relationship between cellulose nanocrystal dispersion and strength. Constr Build Mater 119:71-79

Cappellari M, Daubresse A, Chaouche M (2013) Influence of organic thickening admixtures on the rheological properties of mortars: Relationship with water-retention. Constr Build Mater 38:950-961

Claramunt J, Ventura H, Toledo Filho RD, Ardanuy M (2019) Effect of nanocelluloses on the microstructure and mechanical performance of CAC cementitious matrices. Cem Concr Res 119:64-76

Dillinger A, Esteban L (2014) Experimental evaluation of reservoir quality in Mesozoic formations of the Perth Basin (Western Australia) by using a laboratory low fi eld Nuclear Magnetic Resonance. Mar Pet Geol 57:455-469

Ding Y, Liu JP, Bai YL (2020) Linkage of multi-scale performances of nano- $\mathrm{CaCO}_{3}$ modified ultra-high performance engineered cementitious composites (UHP-ECC). Constr Build Mater 234:117418 
Ding Y, Yu K, Mao W, Zhang S (2021) Performance-enhancement of high-strength strain-hardening cementitious composite by nano-particles: Mechanism and property characterization. Struct Concr 1-15

Escalante-Garcia JI (2003) Nonevaporable water from neat OPC and replacement materials in composite cements hydrated at different temperatures. Cem Concr Res 33:1883-1888

Ez-zaki H, Riva L, Bellotto M, et al (2021) Influence of cellulose nanofibrils on the rheology, microstructure and strength of alkali activated ground granulated blast-furnace slag: a comparison with ordinary Portland cement. Mater Struct 54:1-18

Fu T, Montes F, Suraneni P, et al (2017) The influence of cellulose nanocrystals on the hydration and flexural strength of Portland cement pastes. Polymers (Basel) 9

Ghafari E, Costa H, Júlio E (2015) Critical review on eco-efficient ultra high performance concrete enhanced with nano-materials. Constr Build Mater 101:201-208

Goncalves J, El-Bakkari M, Boluk Y, Bindiganavile V (2019) Cellulose nanofibres (CNF) for sulphate resistance in cement based systems. Cem Concr Compos 99:100-111

Habibi Y, Chanzy H, Vignon MR (2006) TEMPO-mediated surface oxidation of cellulose whiskers. Cellulose 13:679-687

Hisseine OA, Basic N, Omran AF, Tagnit-Hamou A (2018a) Feasibility of using cellulose filaments as a viscosity modifying agent in self-consolidating concrete. Cem Concr Compos 94:327-340

Hisseine OA, Omran AF, Tagnit-Hamou A (2018b) Influence of cellulose filaments on cement paste and concrete. J Mater Civ Eng 30:1-14

Hisseine OA, Soliman NA, Tolnai B, Tagnit-Hamou A (2020) Nano-engineered ultra-high performance concrete for controlled autogenous shrinkage using nanocellulose. Cem Concr Res 137:106217

Hisseine OA, Wilson W, Sorelli L, et al (2019) Nanocellulose for improved concrete performance: A macro-to-micro investigation for disclosing the effects of cellulose filaments on strength of cement systems. Constr Build Mater 206:84-96.

Klemm D, Kramer F, Moritz S, et al (2011) Nanocelluloses: A new family of nature-based materials. Angew Chemie Int Ed 50:5438-5466

Kumar R, Bhattacharjee B (2003) Porosity, pore size distribution and in situ strength of concrete. Cem Concr Res 33:155-164

Li B, Xu W, Kronlund D, et al (2015) Cellulose nanocrystals prepared via formic acid hydrolysis followed by TEMPO-mediated oxidation. Carbohydr Polym 133:605-612

Li L, Cai Z, Yu K, et al (2019) Performance-based design of all-grade strain hardening cementitious composites with compressive strengths from $40 \mathrm{MPa}$ to $120 \mathrm{MPa}$. Cem Concr Compos 97:202-217

Li M, Li VC (2013) Rheology, fiber dispersion, and robust properties of Engineered Cementitious Composites. Mater. Struct. (2013) 405-420

Li Q, Gao X, Xu S (2016) Multiple effects of nano- $\mathrm{SiO}_{2}$ and hybrid fibers on properties of high toughness fiber reinforced cementitious composites with high-volume fly ash. Cem Concr Compos $72: 201-212$ 
Li VC (2019) Engineered cementitious composites (ECC): Bendable concrete for sustainable and resilient infrastructure.

Li VC, Leung CKY (1992) Steady-state and multiple cracking of short random fiber composites. J Eng Mech 118:2246-2264

Liu QL, Peng YJ, Liang L, et al (2019) Effect of cellulose nanocrystals on the properties of cement paste. J Nanomater 2019:1-8

Lu C, Lu Z, Li Z, Leung CKY (2016) Effect of graphene oxide on the mechanical behavior of strain hardening cementitious composites. Constr Build Mater 120:457-464

Ma H, Cai J, Lin Z, et al (2017) CaCO3 whisker modified Engineered Cementitious Composite with local ingredients. Constr Build Mater 151:1-8

Montes F, Fu T, Youngblood JP, Weiss J (2020) Rheological impact of using cellulose nanocrystals (CNC) in cement pastes. Constr Build Mater 235:117497

Moon RJ, Martini A, Nairn J, et al (2011) Cellulose nanomaterials review: Structure, properties and nanocomposites. Chem Soc Rev 40:3941-3994

Muller ACA, Scrivener KL, Gajewicz AM, McDonald PJ (2013) Densification of C-S-H measured by 1H NMR relaxometry. J Phys Chem C 117:403-412

Pan J, Cai J, Ma H, Leung CKY (2018) Development of multiscale fiber-reinforced engineered cementitious composites with PVA fiber and $\mathrm{CaCO}_{3}$ whisker. J Mater Civ Eng 30:1-9

Pane I, Hansen W (2005) Investigation of blended cement hydration by isothermal calorimetry and thermal analysis. Cem Concr Res 35:1155-1164

Sahmaran M, Bilici Z, Ozbay E, et al (2013) Improving the workability and rheological properties of Engineered Cementitious Composites using factorial experimental design. Compos Part B Eng 45:356-368

Santos RF, Ribeiro JCL, Franco de Carvalho JM, et al (2021) Nanofibrillated cellulose and its applications in cement-based composites: A review. Constr Build Mater 288:123122. https://doi.org/10.1016/j.conbuildmat.2021.123122

She AM, Yao W, Yuan WC (2013) Evolution of distribution and content of water in cement paste by low field nuclear magnetic resonance. J Cent South Univ 20:1109-1114

Wei J, Cen K (2019) Empirical assessing cement $\mathrm{CO}_{2}$ emissions based on China's economic and social development during 2001-2030. Sci Total Environ 653:200-211

Weng L, Wu Z, Liu Q (2019) Evaluating damage and microcracking behavior of granite using NMR testing under different levels of unconfined compression. Int J Geomech 19:1-15 Xi B, Zhou Y, Yu K, et al (2020) Use of nano- $\mathrm{SiO}_{2}$ to develop a high performance green lightweight engineered cementitious composites containing fly ash cenospheres. J Clean Prod 262:121274

Xu QH, Li WG, Cheng ZL, et al (2014) TEMPO/NaBr/NaClO-mediated surface oxidation of nanocrystalline cellulose and its microparticulate retention system with cationic polyacrylamide Xu S, Lyu Y, Xu S, Li Q (2019) Enhancing the initial cracking fracture toughness of steelpolyvinyl alcohol hybrid fibers ultra high toughness cementitious composites by incorporating multi-walled carbon nanotubes. Constr Build Mater 195:269-282 
Xu S, Reinhardt HW (2000) A simplified method for determining double-K fracture parameters for three-point bending tests. Int J Fract 104:181-209

Yang E, Şahmaran M, Yang Y, Li V (2009) Rheological Control in Production of Engineered Cementitious Composites. ACI Mater J 106:357-366

Yang EH, Yang Y, Li VC (2007) Use of high volumes of fly ash to improve ECC mechanical properties and material greenness. ACI Mater J 104:620-628

Yu J, Zhang M, Li G, et al (2020) Using nano-silica to improve mechanical and fracture properties of fiber-reinforced high-volume fly ash cement mortar. Constr Build Mater 239:117853

Yu K, Wang Y, Yu J, Xu S (2017) A strain-hardening cementitious composites with the tensile capacity up to $8 \%$. Constr Build Mater 137:410-419

Yu KQ, Yu JT, Dai JG, et al (2018) Development of ultra-high performance engineered cementitious composites using polyethylene (PE) fibers. Constr Build Mater 158:217-227

Zhang A, Yang W, Ge Y, et al (2020a) Study on the hydration and moisture transport of white cement containing nanomaterials by using low field nuclear magnetic resonance. Constr Build Mater 249:118788

Zhang D, Jaworska B, Zhu H, et al (2020b) Engineered Cementitious Composites (ECC) with limestone calcined clay cement (LC $\left.{ }^{3}\right)$. Cem Concr Compos 114:103766

Zhao H, Qin X, Liu J, et al (2018) Pore structure characterization of early-age cement pastes blended with high-volume fly ash. Constr Build Mater 189:934-946

Zhou Y, Zheng S, Huang X, et al (2021) Performance enhancement of green high-ductility engineered cementitious composites by nano-silica incorporation. Constr Build Mater 281:122618 